Manuscript Number: JQSR-D-15-00402R1

Title: The timing of Mediterranean sapropel deposition relative to insolation, sea-level and African monsoon changes

Article Type: Research paper

Keywords: Eastern Mediterranean; sapropels; African monsoon; sea level; ice sheets; insolation; precession; meltwater pulses

Corresponding Author: Dr. Katharine Mary Grant, PhD

Corresponding Author's Institution: The Australian National University

First Author: Katharine Mary Grant, PhD

Order of Authors: Katharine Mary Grant, PhD; Rosina Grimm; Uwe Mikolajewicz; Gianluca Marino; Martin Ziegler; Eelco J Rohling

Abstract: The Mediterranean basin is sensitive to global sea-level changes and African monsoon variability on orbital timescales. Both of these processes are thought to be important to the deposition of organicrich sediment layers or 'sapropels' throughout the eastern Mediterranean, yet their relative influences remain ambiguous. A related issue is that an assumed 3-kyr lag between boreal insolation maxima and sapropel midpoints remains to be tested. Here we present new geochemical and icevolume-corrected planktonic foraminiferal stable isotope records for sapropels S1 (Holocene), S3, S4, and S5 (Marine Isotope Stage 5) in core LC21 from the southern Aegean Sea. The records have a radiometrically constrained chronology that has already been synchronised with the Red Sea relative sea-level record, and this allows detailed examination of the timing of sapropel deposition relative to insolation, sea-level, and African monsoon changes. We find that sapropel onset was near-synchronous with monsoon run-off into the eastern Mediterranean, but that insolationsapropel/monsoon phasings were not systematic through the last glacial cycle. These latter phasings instead appear to relate to sea-level changes. We propose that persistent meltwater discharges into the North Atlantic (e.g., at glacial terminations) modified the timing of sapropel deposition by delaying the timing of peak African monsoon run-off. These observations may reconcile apparent model-data offsets with respect to the orbital pacing of the African monsoon. Our observations also imply that the previous assumption of a systematic 3-kyr lag between insolation maxima and sapropel midpoints may lead to overestimated insolationsapropel phasings. Finally, we surmise that both sea-level rise and monsoon run-off contributed to surface-water buoyancy changes at times of sapropel deposition, and their relative influences differed per sapropel case, depending on their magnitudes. Sea-level rise was clearly important for sapropel S1, whereas monsoon forcing was more important for sapropels S3, S4, and S5. 
$18^{\text {th }}$ March 2016

Editor

Quaternary Science Reviews

Dear Henning,

On behalf of all authors, I hereby submit our revised manuscript "The timing of Mediterranean sapropel deposition relative to insolation, sea-level and African monsoon changes" for publication as an article in Quaternary Science Reviews.

We have addressed all comments of both reviewers by incorporating their suggestions into the text, and we also include results from the Kandiano et al. (2014) study in our revised Figure 4 and in the discussion of meltwater effects in section 3.2. Figures 1 and $3 \mathrm{~b}$ have also been slightly amended, and the reference list has been extended in order to adequately address the reviewers' suggestions. Line references to added/amended text are given in our response to reviewers. The changes have not altered our original conclusions, but they have enriched the manuscript by providing a more comprehensive investigation of the environmental factors that could have contributed to negative $\delta^{18} \mathrm{O}$ anomalies in the Mediterranean at (or near) times of sapropel deposition.

We thank you for your patience in the revision process.

Yours sincerely,

Katharine Grant
Research School of Earth Sciences

The Australian National University

Tel: (+61) 0261253241

Fax: (+61) 0261250738

katharine.grant@anu.edu.au 


\title{
The timing of Mediterranean sapropel deposition relative to insolation, sea-level and
}

\section{African monsoon changes}

\author{
K.M. Grant ${ }^{*}$, R. Grimm ${ }^{2}$, U. Mikolajewicz ${ }^{2}$, G. Marino ${ }^{1}$, M. Ziegler ${ }^{3}$, E.J. Rohling ${ }^{1,4}$
}

1. Research School of Earth Sciences, The Australian National University, Canberra, ACT 2601, Australia

2. Max-Planck-Institute for Meteorology, Bundesstrasse 53, 20146 Hamburg, Germany

3. Department of Earth Sciences, University of Utrecht, Budapestlaan 455, Utrecht 3584 CD, The Netherlands

4. Ocean and Earth Science, University of Southampton, National Oceanography Centre, European Way, Southampton SO14 3ZH, UK

* Corresponding author. E-mail address: katharine.grant@anu.edu.au (K.M. Grant)

Keywords: Eastern Mediterranean, sapropels, African monsoon, sea level, ice sheets, insolation, precession, meltwater pulses.

\section{Abstract}

2 The Mediterranean basin is sensitive to global sea-level changes and African monsoon

3 variability on orbital timescales. Both of these processes are thought to be important to the

4 deposition of organic-rich sediment layers or 'sapropels' throughout the eastern

5 Mediterranean, yet their relative influences remain ambiguous. A related issue is that an

6 assumed 3-kyr lag between boreal insolation maxima and sapropel mid-points remains to be

7 tested. Here we present new geochemical and ice-volume-corrected planktonic foraminiferal

8 stable isotope records for sapropels S1 (Holocene), S3, S4, and S5 (Marine Isotope Stage 5)

9 in core LC21 from the southern Aegean Sea. The records have a radiometrically constrained

10 chronology that has already been synchronised with the Red Sea relative sea-level record, and

11 this allows detailed examination of the timing of sapropel deposition relative to insolation,

12 sea-level, and African monsoon changes. We find that sapropel onset was near-synchronous 
13 with monsoon run-off into the eastern Mediterranean, but that insolation-sapropel/monsoon

14 phasings were not systematic through the last glacial cycle. These latter phasings instead

15 appear to relate to sea-level changes. We propose that persistent meltwater discharges into the

16 North Atlantic (e.g., at glacial terminations) modified the timing of sapropel deposition by

17 delaying the timing of peak African monsoon run-off. These observations may reconcile

18 apparent model-data offsets with respect to the orbital pacing of the African monsoon. Our

19 observations also imply that the previous assumption of a systematic 3-kyr lag between

20 insolation maxima and sapropel midpoints may lead to overestimated insolation-sapropel

21 phasings. Finally, we surmise that both sea-level rise and monsoon run-off contributed to

22 surface-water buoyancy changes at times of sapropel deposition, and their relative influences

23 differed per sapropel case, depending on their magnitudes. Sea-level rise was clearly

24 important for sapropel S1, whereas monsoon forcing was more important for sapropels S3,

25 S4, and S5. 


\section{Introduction}

The Mediterranean basin is an ideal natural laboratory for understanding the dynamic interplay between key climatic and hydrological processes on a range of timescales. Over millennial and longer intervals, changes in global ice volume and African monsoon dynamics are both registered in eastern Mediterranean marine sediments (Rohling et al., 2014, 2015). Detailed understanding of how these processes interact and translate into sedimentary signals is far from complete, and first requires deeper insights into a characteristic feature of these sediments: the periodic deposition of organic-rich layers, or "sapropels", in the eastern basin (for overviews, see Rossignol-Strick 1985; Rohling and Gieskes, 1989; Rohling, 1994; Emeis et al., 1996; Cramp and O'Sullivan, 1999; Rohling et al., 2015, and references therein).

The formation of these sapropels has been attributed to combinations of surface-water freshening, reduced deep-water ventilation, and increased export production (e.g., RossignolStrick et al., 1982; Rossignol-Strick, 1985; Rohling, 1994; Higgs et al., 1994; Emeis et al., 1996; Jorissen, 1999; Thomson et al., 1999; Mercone et al., 2001; Casford et al, 2003; AbuZied et al., 2008; Schmiedl et al., 2010). The main driver behind these processes was a relative increase in surface-layer buoyancy, and the mechanism behind this buoyancy forcing has long been attributed to monsoon-related freshwater inputs into the eastern Mediterranean in response to periodic northward shifts of the intertropical convergence zone (ITCZ). Such shifts were associated with minima in the precession cycle (hence maxima in boreal summer insolation), which caused the summer monsoon rain belt to intensify and migrate north over river catchments and North African wadi systems that drain into the eastern Mediterranean, including the Nile (e.g., Rossignol-Strick et al., 1982; Rossignol-Strick, 1985; Rohling, 1999; 
Rohling and De Rijk, 1999; Rohling et al., 2002, 2004; Larrasoaña et al., 2003; Scrivner et

al., 2004; Bianchi et al., 2006; Marino et al., 2007, 2009; Osborne et al., 2008, 2010).

This accepted scenario of surface buoyancy forcing primarily due to African monsoon changes has recently been challenged for the most recent (early to middle Holocene) sapropel 'S1' (Grimm et al., 2015). Based on comprehensive simulations with a 3-dimensional oceancirculation model coupled to a biogeochemical model and including a sediment module, Grimm et al. (2015) concluded that the evolution of deep-water anoxia prior to S1 formation was initiated by sea-level rise and sea surface warming, and that monsoon-related (i.e., freshwater and nutrient input) forcings were not the sole cause for S1 formation because simulated deep-water oxygen depletion started before the onset of enhanced monsoon runoff. However, the study also acknowledged that monsoon forcing potentially played a significant role in determining the vertical extent of anoxia during S1 deposition. These findings lead to the question of whether other sapropels were also intrinsically linked - at

64 least in part - to episodes of global ice melt. If so, this would represent a paradigm shift to the common narrative of how sapropels were formed.

66

67 A link between sapropel formation and the melting of northern hemisphere ice sheets was proposed in early studies of Mediterranean sediments (e.g., Kullenberg, 1951; Olaussen, 1960; Ryan, 1972). More recently, Troelstra et al. (1991) suggested that glacial meltwater contributed towards preconditioning the Mediterranean for sapropel formation by lowering surface-water salinities. They also suggested that this preconditioning process was interrupted by the cold Younger Dryas (YD) interval. Rohling (1994) substantiated these claims using a simple hydraulic model (based on Rohling and Bryden, 1994), by demonstrating that both monsoon-related freshwater forcing and deglaciation may have contributed to S1 formation. 
Rohling (1994) also suggested that a lag in S1 deposition relative to the nearest insolation maximum may relate to the $\mathrm{YD}$, which would have interrupted the progressive deterioration of deep-water ventilation (hence anoxia) necessary for sapropel formation.

Observational datasets to resolve the monsoon-versus-deglaciation question must include high-resolution records of sapropel deposition, (east) African monsoon variability, and icevolume/sea-level change on robust and chronologically consistent timescales. Such datasets have not been available until recently (Grant et al., 2012, 2014). A key issue in this respect is the fact that a widely accepted astronomically tuned timescale for Mediterranean sediments assumes a 3-kyr lag between precession minima and sapropel mid-points (Hilgen et al., 1993; Lourens et al., 1996, 2004). This assumption was derived from direct radiometric age constraints for sapropel S1 (e.g., Lourens et al., 1996; Mercone et al., 2000; Casford et al., 2007; De Lange et al., 2008). Ziegler et al. (2010a) argued that radiometrically dated oxygen isotope records derived from Chinese speleothems could be used as a tuning target for eastern Mediterranean sapropels, in order to test if the specific S1 phase relationship can be extrapolated to older sapropels. They found that the lag is variable for older sapropels but that on average the assumption of a $\sim 3 \mathrm{kyr}$ lag is a good approximation for the Late Pleistocene.

Here we examine the detailed timing of sapropel deposition relative to insolation, sea-level, and African monsoon changes, using highly resolved, co-registered signals (i.e., measured on the same sample suite) of monsoon-related run-off and sapropels S1, S3, S4 and S5 in eastern Mediterranean core LC21 (southeastern Aegean Sea; Fig. 1). These records have a radiometrically constrained chronology which has already been synchronised (Grant et al., 2012) with the Red Sea relative sea-level (RSL) record (Siddall et al., 2003, 2004; Rohling et al., 2009), so inferred phase relationships between sapropels, monsoon forcing, and sea-level 
100 changes are robust within quantified uncertainties. It has been demonstrated that the Red Sea

101 RSL record closely approximates global (eustatic) sea-level variations (see discussion and

102 glacial isostatic modelling in Grant et al., 2014), which in turn reflect global ice-volume

103 variability on glacial-interglacial timescales. We can therefore use the tightly constrained

104 relationships in our dataset to remove ice-volume effects from the LC21 $\delta^{18} \mathrm{O}$ record of the

105 planktonic foraminifer Globigerinoides ruber (white) $\left(\delta^{18} \mathrm{O}_{\text {ruber }}\right)$, to produce a robust,

106 deconvolved climate and hydrological record for the eastern Mediterranean, which extends

107 over the entire last glacial cycle. We also present new sediment geochemical records from

108 core LC21 that accurately delineate its sapropel intervals. By examining timing relationships

109 - on an internally consistent, U/Th-based chronology - between sapropel deposition and

110 changes in sea level, insolation and African monsoon run-off, we seek to clarify current

111 understanding of sapropel formation mechanisms under different glacial boundary conditions.

112 It is important to emphasise here that current knowledge of sapropel formation is largely

113 based on sapropel S1, followed by S5, because these are the most studied sapropels. Yet S1

114 was relatively weakly developed and was associated with lower insolation forcing, compared

115 to other sapropels. Also, both S1 and S5 were deposited after large deglaciations. These

116 sapropels are therefore not typical of all sapropels, hence the need to examine a range of

117 sapropels with different magnitudes of the postulated forcings.

119 An additional incentive for more detailed study of the dynamics behind sapropel formation is

120 the recent development of a method to reconstruct past sea-level changes using eastern

121 Mediterranean sediments (Rohling et al., 2014). This method relies on the sensitivity of eastern Mediterranean seawater $\delta^{18} \mathrm{O}$ to glacial-interglacial sea-level changes in the Gibraltar

123 Strait. However, the conversion of Mediterranean $\delta^{18} \mathrm{O}$ to sea level is not systematically

124 straightforward, due to the periodic influx of ${ }^{18} \mathrm{O}$-depleted monsoon run-off into the eastern 
125 Mediterranean. As a result, the Mediterranean sea-level method currently involves identifying sapropel intervals and removing them from the sea-level reconstruction. A better understanding of eastern Mediterranean $\delta^{18} \mathrm{O}$ changes across sapropel intervals, as presented in this study, will therefore contribute towards improving the Mediterranean sea-level method.

\section{Methods}

\subsection{Geochemical analyses}

Scanning x-ray fluorescence (XRF) elemental analyses of the archive halves of sediment core

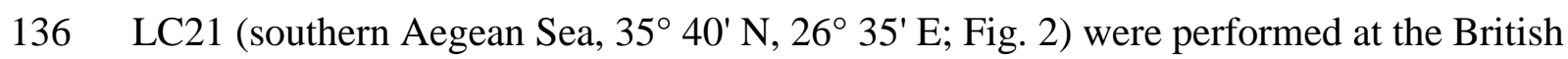

137 Ocean Sediment Core Research Facility (BOSCORF) at the National Oceanography Centre,

138 Southampton, using an Itrax XRF core scanner (Cox Analytical Systems, Gothenburg,

139 Sweden). XRF data were collected every $0.5 \mathrm{~mm}$ down-core using a molybdenum tube set at

$14030 \mathrm{kV}$ and $30 \mathrm{~mA}$, and a sampling time of 40 seconds directly at the core surface. The exposed core surface was covered with a 4 micron thin SPEX Certi Prep Ultralene1 foil to avoid contamination of the XRF measurement unit and desiccation of the sediment.

143 Subsequent sub-sampling at continuous 1-cm intervals and stable isotope analyses of the

144 same core halves have been described in Grant et al. (2012). The foraminiferal stable oxygen

145 and carbon isotope records discussed below are for the surface-dwelling species

146 Globigerinoides ruber (white) $\left(\delta^{18} \mathrm{O}_{\text {ruber }}, \delta^{13} \mathrm{C}_{\text {ruber }}\right)$ and the sub-surface dwelling species

147 Neogloboquadrina pachyderma (dextral) $\left(\delta^{18} \mathrm{O}_{\mathrm{pac}}, \delta^{13} \mathrm{C}_{\mathrm{pac}}\right)$ (cf. Rohling et al., 2004). Tests of

148 these species were selected from $>300 \mu \mathrm{m}$ and $150-300 \mu \mathrm{m}$ sieved sediment fractions,

149 respectively (see Methods in Grant et al., 2012). 
153 Four sapropels (S1, S3, S4, S5) are visibly identified in core LC21 by distinct colour and

154 lithological changes, from olive-grey, fine-grained nannofossil ooze/clay admixtures to much

155 darker layers rich in organic matter (sapropels) (Fig. 2). An 'interruption' to sapropel deposition is evident in S4 and to a lesser extent in S1 (Fig. 2). Because redox reactions at the sediment-seawater interface, and within sediments, can cause downward reduction at the sapropel base and downward oxidation (or 'burn down') at the sapropel top, sapropel

159 boundaries are best identified using elements that are enriched in sapropels and that

160 subsequently exhibit conservative behaviour within sediments (Thomson et al., 1995; De

161 Lange et al., 2008). Barium is ideal for this purpose because it is well-preserved in sediments (Dymond et al., 1992), and enriched in sapropels (Thomson et al., 1995; De Lange et al., 2008) due to its association with export productivity (Dymond et al., 1992). In core LC21,

164 pronounced increases in $\mathrm{Ba}$ at sapropel horizons are accompanied by elevated Vanadium (V).

165 Vanadium is a redox-sensitive element and precipitates under reducing conditions, so although $\mathrm{V}$ can be mobile in sediments, the good agreement between increases in $\mathrm{V}$ and $\mathrm{Ba}$ in core LC21 implies that - in this case - elevated V reliably indicates sapropel boundaries (see Thomson et al., 1995; Nijenhuis et al., 1999; Table 1).

\subsection{Chronology}

172 The age-depth model for core LC21 is described in detail in Grant et al. (2012). Briefly, it is

173 constrained by 14 direct radiocarbon datings and two geochemically 'fingerprinted' tephra

174 layers (the Minoan and Campanian Ignimbrite; Satow et al., 2015) for the interval 0-40 ka 
$175 \mathrm{BP}$, and by process-based correlation to the U/Th-dated Soreq Cave (Israel) speleothem $\delta^{18} \mathrm{O}$

176 record for the interval >40-150 ka BP. All tie-points, radiometric ages (including all Soreq

177 speleothem datings) and their uncertainties were probabilistically assessed in a Bayesian

178 deposition model (using 'OxCal' software, Bronk Ramsey, 2008, 2009). Full error

179 propagation yielded age uncertainties (at $2 \sigma$ ) of $0.4 \pm 0.2 \mathrm{kyr}$ for the interval $0-40 \mathrm{ka} \mathrm{BP}$, and

$1802.0 \pm 0.9 \mathrm{kyr}$ for the interval $>40-150 \mathrm{ka}$ BP. The Red Sea RSL record was synchronised with

181 the LC21 chronology using the LC2 $1 \delta^{18} \mathrm{O}_{\text {pac }}$ record (Grant et al., 2012); this record primarily

182 reflects glacial-interglacial sea-level changes due to a 'glacial concentration' effect on

183 Mediterranean seawater $\delta^{18} \mathrm{O}$ similar to that in the Red Sea (see Rohling, 1999; Grant et al.,

184 2012; and Rohling et al., 2014 for more technical details).

185

186 3. Deconvolving the LC21 $\delta^{18} \mathbf{O}_{\text {ruber }}$ record

187

\subsection{Global ice-volume effects}

189

190 As mentioned before, global ice-volume changes strongly affect Mediterranean seawater $\delta^{18} \mathrm{O}$

191 due to the restriction of exchange flow through the Strait of Gibraltar with lowering of sea

192 level (Rohling, 1999; Rohling et al., 2014). The LC21 $\delta^{18}$ O records therefore contain an

193 important sea-level component (equations 1 and 2); removal of this component from the

$194 \delta^{18} \mathrm{O}_{\text {ruber }}$ record - a proxy for eastern Mediterranean surface-water $\delta^{18} \mathrm{O}$ - will therefore

195 isolate local climatic influences on Mediterranean surface-water $\delta^{18} \mathrm{O}$ (see below).

196 Calculation of this 'residuals' signal first requires conversion of the Red Sea relative sea-

197 level (RSL) record ( $y$ ) into equivalent eastern Mediterranean $\delta^{18} \mathrm{O}$ values $(x)$, based on the

198 upper (equation 1) and lower (equation 2) probability limits for a quadratic relationship

199 determined by Rohling et al. (2014): 


$$
\begin{aligned}
& y=18.23253367-54.32756406 x+2.68013962 x^{2} \\
& y=-19.83859107-54.97329064 x+1.027303677 x^{2}
\end{aligned}
$$

201

202 Because the Red Sea RSL record is unreliable ca 14-23 ka BP (Fig. 3a; see Rohling et al., 203 2009), we have additionally converted into equivalent Mediterranean $\delta^{18} \mathrm{O}$ values the

204 probabilistic sea-level record of Stanford et al. (2011) for the last deglaciation (this record is 205 based on numerous radiometrically dated sea-level indicators). The converted RSL records 206 (Fig. 3a) were normalised to the Late Holocene values for $\delta^{18} \mathrm{O}_{\text {ruber }}$ and then subtracted from

$207 \delta^{18} \mathrm{O}_{\text {ruber }}$. The resultant 'LC21 residuals' are defined by $\delta^{18} \mathrm{O}_{\text {ruber }}$ values lighter/heavier than 208 the upper/lower 95\% probability intervals of the converted RSL records (Fig. 3b). While 209 these probability intervals should account for most of the sea-level/ice-volume component in 210 the $\delta^{18} \mathrm{O}_{\text {ruber }}$ record, we note that there may be two short-term intervals (Section 3.2 below)

211 where glacial influences on Mediterranean $\delta^{18} \mathrm{O}$ have not been captured in the $\delta^{18} \mathrm{O}$-to-sea-

212 level conversion.

213

$214 \quad 3.2$ Meltwater effects

215

216 Observational data and numerical modelling both suggest that the flow of Atlantic water into 217 the Mediterranean was significantly increased during glacial and deglacial North Atlantic 218 freshening events, or 'Heinrich Stadials' (HS), compared to background conditions (e.g., 219 Cacho et al., 1999; Sierro et al., 2005; Rogerson et al., 2010). Sierro et al. (2005)

220 demonstrated that the past five HS were associated with significant ${ }^{18} \mathrm{O}$ depletions in western 221 Mediterranean surface waters, after correcting the foraminifera $\delta^{18} \mathrm{O}$ for temperature and ice222 volume effects. These depletions were observed in the Alboran Sea (core MD95-2043) as 
well as north of the Balearic Islands (core MD99-2343) (Fig. 1). Subsequent studies have

224 corroborated these findings. A western Mediterranean surface water ${ }^{18} \mathrm{O}$ depletion during HS has been documented for: the Gulf of Cadiz during HS1 (Voelker et al., 2006), the Strait of

226 Sicily during HS1 (Essallami et al., 2007), the Gulf of Lion during HS1, HS2 and the YD

227 (Melki et al., 2009; Lombo-Tombo et al., 2015), the Menorca Rise (ODP site 975) during

228 HS11 (Kandiano et al., 2014), and the Alboran Sea (ODP site 976) during HS1 and HS11

229 (Jiménez-Amat and Zahn, 2015) (Fig. 1). Moreover, a synthesis of surface water $\delta^{18} \mathrm{O}$

230 profiles from sediment cores from the Gulf of Cadiz and Alboran Sea covering the last 30

231 ky revealed a reduced Atlantic-Mediterranean $\delta^{18} \mathrm{O}$ gradient during HS (Rogerson et al.,

232 2010). In the same study, a one-dimensional hydraulic control model for the Strait of

233 Gibraltar confirmed that enhanced Atlantic inflow to the Mediterranean would result from a

234 freshening of the North Atlantic associated with iceberg meltwater. Such a scenario has

235 recently been corroborated by hosing experiments with a suite of CMIP5 models

236 (Swingedouw et al., 2013), which show that (isotopically light) meltwater from the subpolar

237 North Atlantic is directed towards the Gulf of Cadiz by the Canary current.

239 Comparison of the LC21 residuals with a record of sea-level change rates ('dRSL') on the 240 same LC21 chronology, and with the (radiometrically dated) timing of meltwater pulse 1a 241 (Deschamps et al., 2012) and HS1 (Álvares-Solas et al., 2011), and with the radiometrically constrained timing of HS11 (Marino et al., 2015) (Fig. 3c), reveals that the timing of large melting events during terminations I and especially II coincides with distinct intervals of

244 negative residuals. The timing of HS3 and HS5 can also potentially be correlated with 245 pronounced negative LC21 residuals ca 28-30 and 46-48 ka, respectively (Fig. 3b), in line 246 with Sierro et al's (2005) observations of surface-water ${ }^{18} \mathrm{O}$ depletions in the western 
247 Mediterranean during the last five HS. This inference is possibly supported by dRSL for HS5, but not for HS3 (Fig. 3c).

250 If we consider sub-surface $\delta^{18} \mathrm{O}$ records from core LC21 and ODP site 975 that have been

251 tuned to the same age model (Marino et al., 2015; Figs. 1, 4a), we observe an isochronous ${ }^{18} \mathrm{O}$ depletion at these sites during HS11. Although on a different age model, a depletion of similar timing and magnitude at ODP site 975 is recorded by surface-water $\delta^{18} \mathrm{O}$ records (Kandiano et al., 2014; Fig. 4b), so the LC21 ${ }^{18} \mathrm{O}$ depletion appears to be consistent with widespread observations from the western Mediterranean. In that case, it seems likely that negative spikes in the LC21 residuals during major deglaciation events are due to North Atlantic (meltwater-related) $\delta^{18} \mathrm{O}$ anomalies propagating into the eastern Mediterranean, and these short-term signals are not captured by the RSL-to- $\delta{ }^{18} \mathrm{O}$ conversion for the Mediterranean (Rohling et al., 2014).

An additional consideration is the direct input of glacial meltwater into the Mediterranean from alpine deglaciation and/or retreat of the European ice sheet (EIS). Regarding alpine meltwater, a synthesis of Mediterranean mountain glacial activity suggests that the last deglaciation was staggered, with several glacial advances/retreats occurring between the last glacial maximum and the Holocene, yet there are no reliably dated records from many areas (see Hughes \& Woodward, 2009). The relatively small glaciers in this region would have responded rapidly to climate change and decayed much faster than extensive ice sheets (Hughes et al., 2006), which implies that the largest meltwater effects on Mediterranean $\delta^{18} \mathrm{O}$ would have occurred early in the deglaciation. It therefore seems unlikely that the negative

270 LC21 residuals ca $15 \mathrm{ka}$ are primarily due to alpine meltwater. Nonetheless, a negative shift in surface water $\delta^{18} \mathrm{O}$ coinciding with HS1 has been recorded in cores from the Rhone 
272 Canyon, in the far north Gulf of Lion (Lombo Tombo et al., 2015), which may reflect

273 enhanced Rhone run-off at that time. Also, Rohling et al. (2015) argued that alpine meltwater

274 from the Rhone offered the most plausible explanation for the onset of the most recent

275 organic rich layer (ORL1) in the western Mediterranean, at $\sim 14.5 \mathrm{ka}$.

277 Even less information about Mediterranean alpine meltwater is available for the penultimate 278 deglaciation. The negative LC21 residuals spike ca $133 \mathrm{ka}$ occurs $\sim 1-2 \mathrm{ky}$ after the onset of termination 2 (i.e., closer to the onset of deglaciation than during termination 1), so alpine meltwater may have contributed to this isotopic depletion in LC21. However, the relatively small volume and ${ }^{18} \mathrm{O}$ depletion of alpine meltwaters compared to global ice sheets means that North Atlantic meltwaters propagating into the eastern Mediterranean would likely dominate any $\delta^{18} \mathrm{O}$ meltwater signals in LC21. Further data are needed to address this question.

Regarding meltwater from European ice sheets, recent work suggests that drainage of the EIS at the end of the last glacial cycle was predominantly into the North Atlantic (Toucanne et al., 2015a), but there is also evidence that meltwater from the Fennoscandian ice sheet (FIS) flowed into the Black Sea during HS1, and that this overflowed into the northern Aegean Sea (Soulet et al., 2013). Other studies of Black Sea sediments, however, suggest generally stable environmental and hydrologic conditions through the last deglaciation until $14.5 \mathrm{ka} \mathrm{BP}$, despite an interruption between 16.5 and $14.8 \mathrm{ka} \mathrm{BP}$ which was linked to input of sediments from a northern source (possibly the FIS) (Major et al., 2006; Bahr et al., 2006, 2008). Those and other studies (Sperling et al., 2003; Rohling et al., 2015) agree that reconnection of the

295 Black Sea with the Mediterranean appears to have been established much later, ca $9 \mathrm{ka} \mathrm{BP.}$

296 There are far fewer robust observations for the penultimate deglaciation, so in view of 
available evidence, we surmise that any input of meltwater from European ice sheets directly into the Mediterranean was likely relatively small for the last deglaciation, and therefore would not significantly affect the $\mathrm{LC} 21 \delta^{18} \mathrm{O}$ residuals.

300

301 In short, the timing, volume and isotopic composition of alpine run-off into the

Mediterranean over glacial-interglacial timeframes is not well constrained. While this

freshwater source cannot be ruled out, the close timing between negative spikes in the LC21 residuals, ${ }^{18} \mathrm{O}$ depletions in the western Mediterranean, and HS suggests that the propagation of meltwater from the North Atlantic into the eastern Mediterranean explains most of the negative LC21 residuals at the end of HS1 and within HS11 (Fig. 3b). This is the first time such an inference has been made for the eastern Mediterranean, and it has important new implications for the interpretation of eastern Mediterranean $\delta^{18} \mathrm{O}$ records, including those from speleothems whose source waters derive from eastern Mediterranean sea-surface water.

\subsection{Local climatic effects}

313 Next we consider local climatic influences on Mediterranean surface-water $\delta^{18} \mathrm{O}$, and how

314 these may manifest in the LC21 residuals. Such influences include sea surface temperature

315 (SST), regional precipitation/evaporation, and African monsoon run-off.

\subsubsection{Temperature}

318 The RSL-to- $\delta{ }^{18} \mathrm{O}$ conversion accounts for glacial-interglacial Mediterranean SST contrasts of

$319+5{ }^{\circ} \mathrm{C}$ (summer) and $+3.5^{\circ} \mathrm{C}$ (winter), with probabilistically determined uncertainties (see

320 Rohling et al., 2014). These gradients are based on reconstructions for the LGM-to-Present

321 (Hayes et al., 2005) and agree with isotope- and alkenone-derived SST estimates (Cita et al., 
322 1977; Emeis et al., 2003). Such reconstructions also imply, however, that the penultimate

323 glacial-interglacial SST gradient in the eastern Mediterranean was up to double that of the

324 LGM-to-Present (Cita et al., 1977; Emeis et al., 2003). In that case, the sharp rise in negative

325 LC21 residuals at the onset of sapropel S5 (Fig. 3b) might partly reflect a SST increase that

326 has not been accounted for in the RSL-to- $\delta^{18} \mathrm{O}$ conversion.

328 We have converted existing SST data for core LC21 (Marino et al., 2007, 2009) to our U/Th329 related chronology (Fig. 5a,b). Although the data only cover the intervals of sapropels S1 and

330 S5, detailed SST reconstructions for the eastern Mediterranean (Emeis et al., 2000, 2002,

3312003 ) suggest that glacial-interglacial SST increases were greater immediately prior to S1

332 and S5 than for S3 and S4. Hence, any temperature effects on the LC21 residuals at the onset

333 of S3 and S4 should be less pronounced than those for S1 and S5. The RSL-to- $\delta^{18} \mathrm{O}$

334 conversion used to calculate the LC21 residuals (Section 3.1) is based on LGM-to-Present

335 temperature gradients; therefore, the residuals record implicitly takes into account any SST

336 increases prior to the onset of sapropels S1, S3 and S4. 'Small-scale' temperature variations

337 are not accounted for in the RSL-to- $\delta^{18} \mathrm{O}$ conversion, although their effect on the LC21

338 residuals at sapropel onset would likely be negligible compared to the larger warming trends.

339 Regarding sapropel S5, the LC21 (Fig. 5b) and comparable SST records (e.g., for southern

340 Aegean core MD40/67 in Emeis et al., 2003) suggest a glacial-interglacial temperature

341 gradient that was $3-4{ }^{\circ} \mathrm{C}$ (equivalent to a maximum of $0.8 \%$ ) greater than that of the last

342 deglaciation. Allowing for this $\sim 1 \%$ change due to SST changes means that at least $0.5 \%$ of

343 the negative shift in residuals at the onset of S5 must still be explained. 
346 Any temperature effects on foraminiferal calcite $\delta^{18} \mathrm{O}$ would be (partly) offset by

347 fractionation effects on seawater $\delta^{18} \mathrm{O}$ due to evaporation. Hence, our inferred depletions in

348 LC21 residuals due to increased SSTs should be viewed as maximum estimates, and were

349 likely lower. The next question is therefore: to what extent do the remaining negative

350 residuals (Fig. 3b) reflect a decrease in net evaporation from the Mediterranean region during

351 times of sapropel deposition? This has long been debated, reflecting the contrasting and/or so

352 far ambiguous proxy evidence (mainly pollen data) for hydrological changes in the eastern

353 Mediterranean region at times of sapropel formation (see Tzedakis, 2007, 2009 and Rohling

354 et al., 2015 for overviews).

356 For example, Kallel et al. $(1997,2000)$ inferred that the salinity of eastern Mediterranean surface waters (SSS) was homogenous during sapropel deposition, and suggested that this reflected an increase in local precipitation. However, a statistical assessment of $\delta^{18} \mathrm{O}$ gradients through the Mediterranean basin for the time of S1 deposition indicated that

360 strongest depletion clearly occurred in the Levantine region, in the vicinity of the Nile outlet

361 (Rohling and De Rijk, 1999). Those authors also contested the calibration of $\delta^{18} \mathrm{O}$ into SSS as used by Kallel et al. $(1997,2000)$, because the modern sea-surface salinity: $\delta^{18} \mathrm{O}$ ratio in the

363 Mediterranean does not hold for periods of enhanced freshwater input to the basin; that objection was further quantified by Rohling (1999) and Rohling et al. (2004). The importance of 'other freshwater sources' (than the Nile) to the eastern Mediterranean at the beginning and end of sapropel S5 deposition was also suggested by Scrivner et al. (2004), based on an apparent disparity between trends in $\mathrm{Nd}$ isotopes and residual $\delta^{18} \mathrm{O}$ (i.e., corrected for temperature and ice-volume effects) across S5 at ODP site 967. However, the Nd record is of lower resolution compared to the $\delta^{18} \mathrm{O}$ residuals, and, even if the offset is real, run-off from the wider North African margin could account for 'other freshwater sources', as was shown 
by Osborne et al. (2008). Palynological studies of the eastern Mediterranean have also inferred an increase in summer precipitation during times of sapropel formation (e.g., Rossignol-Strick, 1987, 1999; Wijmstra et al., 1990; Rossignol-Strick and Paterne, 1999; interpretations, and suggested that drought-resistant species or winter precipitation equivalent to the present-day regime could explain the observed trends, without the need to invoke enhanced summer precipitation. This interpretation is supported by Toucanne et al. (2015b), who inferred an increase in winter precipitation over the northern Mediterranean borderlands (NMB) during warm intervals of interglacials over the past $547 \mathrm{kyr}$, based on a suite of geochemical and lithological tracers of Golo River run-off into the northern Tyrrhenian Sea (core GDEC-4-2, Fig. 1).

In contrast, a comprehensive review of evidence for humidity changes in the Levant over the last two glacial-interglacial cycles concluded that, in general, it was the glacial (rather than interglacial) periods that were wetter (Frumkin et al. 2011). This is quantitatively supported by calculations of Dead Sea (=Lake Lisan) levels over the past 120 ka BP (Rohling, 2013). Similarly, groundwater isotope data suggest that Saharan aquifers were recharged during glacial rather than interglacial periods (Abouelmagd et al., 2012, 2014). However, speleothem growth periods in the Negev Desert (Israel) - indicative of wetter intervals -

390 generally coincide with interglacials and monsoon maxima/precession minima (i.e., sapropel intervals), but not always: the Northern Negev appears to have been arid at $105 \mathrm{ka}$ ( $\approx$ sapropel S4) and $11 \mathrm{ka}(\approx \mathrm{S} 1)$ (Vaks et al., 2006).

394 Despite these apparently disparate findings, a consensus is emerging that they can be 

a high-resolution, fully coupled ocean-atmosphere general circulation model (Bosmans et al., 2015). If we assume the 'winter precipitation' hypothesis to be correct, the key question then is what would be the effect of increased winter rainfall on eastern Mediterranean sea-surface $\delta^{18} \mathrm{O}$, and could that explain negative LC21 $\delta^{18} \mathrm{O}$ residuals during precession minima? In Bosmans et al.'s (2015) simulations, the predicted winter precipitation was not uniform over the Mediterranean but focussed over the Ionian and Levantine Seas, and was associated with local convection rather than eastward propagating storm tracks from the North Atlantic. Interestingly, no increase in either summer or winter rainfall over the NMB during precession minima was indicated, whereas both summer and winter rainfall increased over the Levant. These observations suggest that the effect on surface water $\delta^{18} \mathrm{O}$ of any precipitation increase would be localised; furthermore, this effect would likely be either negligible (i.e., balanced by increased evaporation from the same basin) or an increase in $\delta^{18} \mathrm{O}$ values (if locally evaporated moisture precipitated outside the catchments of the eastern Mediterranean basin)

411 (Rohling et al., 2015).

413 To further investigate these effects, we developed a record of 'Soreq excess $\delta^{18} \mathrm{O}^{\prime}$ ( $\left(\delta^{18} \mathrm{O}_{\text {SOREQ }}\right.$

$414 \mathrm{XS}$ ) for the Soreq cave (Israel) speleothem $\delta^{18} \mathrm{O}$ record $\left(\delta^{18} \mathrm{O}_{\text {speleo }}\right)$ by subtracting the LC21

$415 \delta^{18} \mathrm{O}_{\text {ruber }}$ record from it (Fig. 6). The $\delta^{18} \mathrm{O}_{\text {SOREQ Xs }}$ record thus represents a deconvolved local 416 eastern Mediterranean climate signal, from which any bias related to monsoon/riverine run-

417 off or global glacial cycles has been removed. This calculation is possible because $i$ ) there is

418 a direct evaporation-precipitation link between the $\delta^{18} \mathrm{O}$ composition of eastern

419 Mediterranean surface waters and speleothems from the Levant (Matthews et al., 2000; Bar-

420 Matthews et al., 2003; McGarry et al., 2004; Kolodny et al., 2005; Almogi-Labin et al., 2009; 
421 Marino et al., 2009; Grant et al., 2012), ii) temperature variations in eastern Mediterranean

422 surface waters and Soreq cave are coupled (Bar-Matthews et al., 2003; Affek et al., 2008),

423 and iii) the $\delta^{18} \mathrm{O}_{\text {speleo }}$ and $\delta^{18} \mathrm{O}_{\text {ruber }}$ records have been previously synchronised (Grant et al.,

424 2012). We first interpolated the $\delta^{18} \mathrm{O}_{\text {speleo }}$ and $\delta^{18} \mathrm{O}_{\text {ruber }}$ records to the same age-steps,

425 subtracted the mean from each record so that they were centred about a mean of zero, and

426 then subtracted the zero-centralised $\delta^{18} \mathrm{O}_{\text {ruber }}$ from the zero-centralised $\delta^{18} \mathrm{O}_{\text {speleo. }}$. The

427

uncertainty of $\delta^{18} \mathrm{O}_{\text {SOREQ XS }}$ about the mean value $( \pm 0.38$ at $2 \sigma)$ was calculated using a root

428

mean squares calculation, and combines uncertainties for the average Late Holocene value of

$\delta^{18} \mathrm{O}_{\text {speleo }}( \pm 0.29)$ and $\delta^{18} \mathrm{O}_{\text {ruber }}( \pm 0.24)$.

430

431 The $\delta^{18} \mathrm{O}_{\text {SOREQ Xs }}$ values suggest that most of the S1, S3, and S4 intervals were not

characterised by systematically wetter/warmer conditions in the Levant (Fig. 6b), although an

inferred decrease in net evaporation during brief $(<1 \mathrm{ky})$ periods within the latter halves of

sapropels S1 and S4 can account for some of the variability in the residuals at those times. In

contrast, $\delta^{18} \mathrm{O}_{\text {SOREQ XS }}$ implies intermittently wetter/warmer conditions at Soreq Cave during sapropel S5 (Fig. 6b). These interpretations are broadly consistent with the findings of Vaks et al. (2006), who noted that not all monsoon maxima/precession minima were associated with more humid intervals in the Levant. Specifically, both $\delta^{18} \mathrm{O}_{\text {SOREQ Xs }}$ and the Vaks et al. (2006) study imply that the interval of S5 was generally more humid, while the S4 and S1

440 intervals were relatively arid. The $\delta^{18} \mathrm{O}_{\text {SOREQ Xs }}$ record suggests that the $\mathrm{S} 3$ interval was also 441 relatively arid, although the Vaks et al. (2006) study suggests that this interval was more

442 humid. We note that the Bosmans et al. (2015) 'precession minima' simulations were

443 performed for maximum eccentricity only, i.e., equivalent to the orbital configuration for S5;

444 future modelling of precession minima of different intensities is therefore needed to fully

445 validate the observational data. Finally, positive $\delta^{18} \mathrm{O}_{\text {SOREQ XS }}$ values in the earliest part of S5 
446 imply drier conditions in the eastern Mediterranean at that time. This is consistent with

447 evidence for a peak in Mediterranean sclerophylls during the initial period (first $~ 2 \mathrm{kyr}$ ) of

448 interglacials, which strongly suggests summer aridity (Tzedakis et al., 2002, 2003; Tzedakis,

449 2009, and references therein). Hence, the sharp decrease in LC21 residuals at the onset of S5

450 (Fig. 3b) is not likely to represent decreased net evaporation in the eastern Mediterranean

451 region.

452

453 To sum up, minimal climatic influences can be attributed to the LC21 residuals through S1,

454 S3 and S4, and a maximum of -1\%o (likely less) of the LC21 residuals through sapropel S5

455 can be explained by local climate changes. We therefore conclude that most of the abrupt

456 negative shifts in LC21 residuals at the onset of sapropels are unlikely to be due to local

457 climatic changes, and instead reflect external, monsoon-related run-off into the eastern

458 Mediterranean from the Nile and wider North African margin (e.g., Rossignol-Strick, 1985;

459 Rohling, 1999; Rohling et al., 2002; Scrivner et al., 2004; Osborne et al., 2008, 2010).

460

461 4. A proxy for African monsoon run-off

462

463 A useful means for validating our conclusion that the LC21 residuals predominantly reflect

464 African monsoon run-off into the eastern Mediterranean, is to compare them with past

465 changes in atmospheric methane $\left(\mathrm{CH}_{4}\right)$ concentrations. Such changes are closely related to

466 the extent of tropical wetlands, and therefore also to changes in monsoon precipitation

467 (Chappellaz et al., 1990; Spahni et al., 2011). Alternatively, we could compare the residuals

468 to other African monsoon proxy records, yet this is not straightforward due to $i$ ) large spatial

469 and temporal heterogeneity in African monsoon precipitation, $i i$ ) variable threshold responses

470 among different precipitation/monsoon proxies, iii) a dearth of suitable records extending 
from the Holocene to MIS 5e, and $i v$ ) chronological uncertainties within and between different proxy records (see Gasse, 2000). While ice-core $\mathrm{CH}_{4}$ records are not without chronological uncertainties, and do not unambiguously reflect monsoon variability (for instance, they are also coupled to northern hemisphere temperature fluctuations; see Baumgartner et al., 2014), they are advantageous because they provide a continuous, high resolution, well-mixed (spatially and temporally) signal over the entire last glacial cycle that is strongly coupled to boreal tropical hydrological changes. We therefore compare our LC21 residuals with ice-core $\mathrm{CH}_{4}$ records from Greenland (North Greenland Ice-core Project (NGRIP); Baumgartner et al., 2014) and from Antarctica (EPICA Dronning Maud Land 480 (EDML); Schilt et al., 2010; Bazin et al., 2013) (Fig. 5). Figure 5 reveals good agreement in 481 the timing of abrupt $\mathrm{CH}_{4}$ increases and negative LC21 residuals prior to sapropel onset, for all four sapropel intervals considered here.

The agreement is excellent for S3 and S5 at sapropel onset (Fig. 5b,c). A smaller peak in the LC21 residuals before S5 (ca $132 \mathrm{ka}$ ) can be (partly) explained by isotopically light meltwater reaching the eastern Mediterranean (section 3.2), so we do not compare the LC21 residuals and $\mathrm{CH} 4$ over this interval. For $\mathrm{S} 4$, methane levels start to increase $\sim 0.5-1 \mathrm{kyr}$ before the LC21 residuals decrease (Fig. 5d). While this offset is within the age uncertainties of both records, the timing of the LC21 residuals decrease is very closely aligned with a marked increase in $\delta^{18} \mathrm{O}$ in a U/Th-dated speleothem ('NALPS'; Boch et al., 2011) from the

491 European Alps (Fig. 5d). The NALPS record primarily reflects high-latitude temperature 492 variations in the wider North Atlantic, and is remarkably similar to NGRIP temperature reconstructions (Boch et al., 2011). Given that NGRIP methane and temperature records are

494 directly in phase over the last glacial cycle (Baumgartner et al., 2014) (Fig. 5d), the U/Thdated NALPS record can be used to independently validate the NGRIP chronology in this 
interval. In detail, this reveals a clear offset between shifts in the NALPS and NGRIP records prior to the onset of sapropel S4 and within the S4 interruption (Fig. 5d), which suggests that the NGRIP chronology may be $\sim 1$ ky too old at around 108 ka BP. Interestingly, our U/Thbased chronology for the LC21 residuals yields a much closer agreement to the U/Th-dated

500 NALPs record than to the NGRIP methane and temperature records (Fig. 5d). Thus, the $\mathrm{CH}_{4}$ and LC21 residuals records may be more closely in phase than figure $5 \mathrm{~d}$ suggests, once the apparent age correction is implemented to the NGRIP records.

504 For sapropel S1, the timing of two abrupt $\mathrm{CH}_{4}$ rises appears to be slightly offset from

505 decreases in the LC21 residuals (Fig. 5a). This offset may simply reflect age model

506 uncertainties (in LC21 and/or the ice cores), yet this is arguably the most reliably dated

507 section of all cores. An alternative explanation is that negative peaks in LC21 residuals at 15.5-14.3 ka BP, $12.5 \mathrm{ka} \mathrm{BP}$, and at 11.8-11.6 ka BP may (partly) relate to meltwater release

509 into the North Atlantic during the last deglaciation. As explained in Section 3.2, such

510 meltwater pulses would bring isotopically light $\delta^{18} \mathrm{O}$ into the Mediterranean, and this has not

511 been accounted for in the RSL-to- $\delta^{18} \mathrm{O}$ conversion which is used to calculate the LC21

512 residuals. A third explanation is that northern hemisphere temperature, rather than tropical

513 precipitation, accounts for most of the $\mathrm{CH}_{4}$ signal at this time. Both the NGRIP temperature

514 and $\mathrm{CH}_{4}$ records clearly show the Bølling-Allerød warm interval ( 13-15 ka BP), which is

515 less apparent in the LC21 residuals (Fig. 5a). Given these various explanations, we do not

516 attempt to interpret the LC21 residuals outside of the peak monsoon run-off interval

517 associated with sapropel S1. In that case, there is generally good agreement between the

518 LC21 residuals and $\mathrm{CH}_{4}$ records from $\sim 11 \mathrm{ka} \mathrm{BP}$ onwards (Fig. 5a). Thus, considering all

519 four sapropels in $\mathrm{LC} 21$, the $\mathrm{CH}_{4}$ records support our inference that the $\mathrm{LC} 21$ residuals 
reliably track African monsoon run-off into the eastern Mediterranean at times of sapropel deposition.

\section{Discussion}

\subsection{Monsoon-sapropel phasing}

526

Our reconstructions suggest that the increases in African monsoon run-off associated with sapropels S3, S4 and S5 are sharply delineated, and coincide closely with the starts of sapropel deposition. For sapropel S1, the onset of the monsoon signal seems somewhat masked in the LC21 residuals, likely due to meltwater effects (Fig. 3; Section 3.2). Nonetheless, an abrupt increase in monsoon run-off to peak values coincides with the onset of S1. These coherent observations suggest that monsoon-related freshwater inputs to the eastern Mediterranean were a primary driver in triggering the onset of sapropel formation, consistent with conventional views (e.g., Rossignol-Strick, 1985; Emeis et al., 1996; Ziegler et al., 2010a).

The timing of sapropels (and monsoonal flooding) relative to insolation/precession, however,

538 varies by up to $\sim 3 \mathrm{kyr}$, irrespective of whether the sapropel onset or mid-point is used for

539 phase calculations (Table 2, Fig. 7). We focus on sapropel mid-point phasings in order to 540 compare our results with previous studies (Lourens, 1994; Lourens et al., 1996, 2004; Ziegler

541 et al., 2010a). The mid-points of sapropels S3 and S4 in core LC21 occurred within 0.1-0.8

542 kyr of precession minima and insolation maxima (Table 2; Fig. 7c,d), whereas the mid-points

543 of sapropels S1 and S5 lag the nearest precession minimum/insolation maximum by 2.1-3.3

544 kyr (Table 2; Fig. 7a,b). Previous studies inferred a lag of $\sim 3 \mathrm{kyr}$ between the mid-point of S1 
and the nearest precession minimum/insolation maximum (Lourens, 1994; Lourens et al., 1996, 2004; Ziegler et al., 2010a), and we find a comparable phase offset for S1. We find that

547 it also appears to be valid for S5, but not for S3 or S4. We note, however, that the mid-point ages for S1, S3, S4 and S5 in Ziegler et al. (2010a) are all within chronological uncertainties of the new mid-point ages presented here, when we consider what Ziegler et al. (2010a) termed "precursory events" of S3 and S4 as part of the sapropel.

551

It is worth bearing in mind that the timing of a sapropel mid-point depends on the duration of sapropel deposition, as noted by Emeis et al. (2003), and this clearly varies (Table 1). In core LC21, the largest discrepancy between sapropel durations is between S1 and S5 (2.4 kyr, Table 1), yet both sapropels exhibit a similar precession-lag. Furthermore, S4 and S5 have similar durations, yet very different insolation phasings (Tables 1,2). Therefore, differences among sapropel mid-point phasings with respect to precession are not simply an artefact of variable sapropel deposition periods. An alternative approach is to consider sapropel-insolation phasings based on the onset rather than mid-point of a sapropel. This makes sense because African monsoon precipitation is influenced by positive vegetationalbedo feedbacks which vary with insolation intensity (Nicholson, 2009). These feedbacks are therefore unlikely to be the same for all sapropels. However, at the onset of elevated monsoon run-off (= sapropel deposition), such feedbacks would not yet have had time to

564 fully develop. Hence, the timing of sapropel onsets should be less biased by feedback processes than the timing of sapropel mid-points. As noted above, in LC21 we observe similar (relative) differences among sapropel-insolation phasings using the onset and mid-

567 point criteria (Table 2), which suggests that our inferred phase relationships are robust. 
569 Regardless of possible explanations for the above phase differences, our observations suggest

570

571

572

573

574

575

576

577

578

579

580

581

582

583

584

585

586

587

588

589

590

591 These results imply that over the last glacial cycle, sapropel deposition was sensitive to sea-

592 level changes, in agreement with Grimm et al.'s (2015) model experiments for sapropel S1. that 1 ) the concept of a consistent 3-kyr lag between precession minima/insolation maxima and an interval of sapropel deposition is valid only within broad uncertainties of a few thousand years, and 2) insolation is not the sole driver of African monsoon dynamics, given that insolation-monsoon phasings do not seem to be consistent among the sapropels considered here.

\subsection{Sea level-sapropel phasing}

In core LC21, the deposition of sapropels S3, S4 and S5 began after sea level had risen to a relative 'highstand', despite differences in the height of these highstands (Fig. 7b-d).

Conversely, sapropel S1 was deposited when sea level was still rising, and its onset occurred $\sim 4$ kyr before a highstand (Fig. 7a). These observations suggest that the relative timing of the Holocene sapropel (S1) was unique for the last glacial cycle. However, when considering rates (dRSL) and amplitudes of sea-level change, rather than RSL itself, we see another pattern, namely a clear discrepancy between sea level-sapropel phasings between early interglacial and glacial-inception periods (Fig. 7). In the interglacial case (S1 and S5), sapropel deposition began after sea-levels had risen $\sim 90 \mathrm{~m}$, and after a 50-75\% reduction in rates of sea-level rise from their peak rates (Fig. 7a,b). In the case of glacial inception times (S3 and S4), the onset of sapropel deposition occurred after substantially smaller sea-level rises ( 15-35 m), and just after sea-level rise rates peaked (Fig. 7c,d).

\footnotetext{
In those experiments, monsoon forcing alone could not explain $\mathrm{S} 1$ formation because the
} 
594 development of deep-water anoxia took several millennia, i.e., longer than the timespan between monsoon onset and S1 deposition. However, Grimm et al.’s (2015) simulations also showed that monsoon forcing nonetheless contributed to S1 deposition because the additional

597 freshwater inputs led to strong changes in density gradients; these in turn affected the vertical

598 extent and duration of S1 anoxia. We observe close timing relationships for both sea-level

599 and monsoon changes among all sapropels considered here, which occurred under a wide range of insolation and ice-volume forcings. We also observe that the relationships with sealevel change are not straightforward, and that different interpretations arise depending on comparison with sea-level itself, or with rates of sea-level change (see below).

603

\subsection{Sapropel formation: sea-level versus monsoon control}

605

606 Our data strongly suggest that the onset of sapropel deposition over the last glacial cycle was

607 sensitive to both sea-level change and monsoonal flooding of the eastern Mediterranean.

608 While increased freshwater input to the Mediterranean from the northern Mediterranean

609 Borderlands (NMB) has frequently been proposed to have also contributed to sapropel

610 formation (section 3.3.2), and cannot be entirely ruled out, the effect of this run-off on net

611 buoyancy forcing has not yet been adequately quantified. Given that most precipitation over

612 the wider eastern Mediterranean (including the NMB) is sourced from the basin itself, that

613 implies little or no net effect on surface buoyancy changes (see section 3.3.2). Hence,

614 monsoon- and deglaciation-related changes in basin hydrography remain the most plausible

615 mechanisms of surface buoyancy forcing at the time of sapropel deposition.

616

617 Given that our data show: $i$ ) synchronous onsets of sapropel deposition and monsoonal 618 flooding into the eastern Mediterranean, and ii) variable sea-level (ice-volume) histories 
619 immediately prior to and at the onset of sapropel deposition among different sapropels,

620 despite broad similarities among these histories, the most straightforward interpretation

621 would be that the onset of sapropel deposition was closely related to monsoon forcing, and

622 not so systematically controlled by deglaciation effects.

623

624 Nonetheless, especially for sapropel S1, a strong sea-level (and warming) influence may still exist (e.g., Grimm et al., 2015) because, out of the four sapropels considered here, $\mathrm{S} 1$ is the only one that was deposited immediately after a substantial sea-level rise, and sea level continued to rise throughout S1 deposition. A link between sapropel S1 formation and 628 deglaciation was first demonstrated quantitatively by Rohling (1994) and Béthoux and Pierre 629 (1999), who showed that the latter would lead to decreased surface- and intermediate-water 630 salinities, which in turn would inhibit deep-water ventilation. This is because rising sea levels 631 would have enhanced the exchange of Atlantic and Mediterranean waters at the Strait of

632 Gibraltar by increasing the cross-sectional area of the strait (e.g., Bryden and Kinder, 1991;

633 Rohling, 1999; Rogerson et al., 2012). The resultant decrease in residence time of

634 Mediterranean waters, combined with the reduced salinity of inflowing Atlantic water due to melting ice sheets, would cause progressive surface buoyancy gain in the Mediterranean

636 (Rohling et al., 2015). This relationship - between sea-level change and Mediterranean

637 salinity - is well-defined and non-linear on glacial-interglacial timeframes (Rohling and 638 Bryden, 1991) (as opposed to the modern stochastic relationship observed inter-annually by 639 Pinardi et al. (2014)).

640

641 A relatively weak insolation maximum during the Holocene provides further support for the 642 proposed role of sea-level rise in S1 deposition, because the monsoon maximum was 643 probably less intense (de Noblet et al., 1996) than for other sapropels (namely S5; Rohling et 
644 al., 2004) and therefore may not have provided sufficient buoyancy forcing (via freshwater

645 run-off) for deep-water stagnation. This argument is somewhat supported by the LC21

646 residuals through $\mathrm{S} 1$, in that they are roughly half the magnitude of those for S5 (Fig. 3),

647 which was deposited during a relatively strong insolation maximum (Fig. 7b).

648 Notwithstanding possible temperature effects on the LC21 residuals, our interpretation is

649 further supported by a detailed study of stable isotopes $\left(\delta^{18} \mathrm{O}, \delta^{13} \mathrm{C}\right)$ in multiple foraminiferal

650 species through sapropels S1 and S5 in the eastern Mediterranean (Rohling et al., 2004). That

651 study concluded that freshwater dilution of surface waters was much reduced during S1

652 compared to S5. Similarly, the duration of S1 is distinctly shorter (4.4 kyr) than that of S5

653 (6.8 kyr) (Table 1), which may be consistent with weaker monsoon-forcing of S1 compared 654 to S5.

655

656 There is little differentiation among the LC21 residuals values for S1, S3 and S4 (Fig. 3b), or 657 among the corresponding insolation values (Fig. 7), implying that sapropels S3 and S4 may

658 have been comparable to S1 in terms of relatively weak monsoon forcing. However, the 659 durations of S3 and S4 exceed that of S1 (Table 1), and opposite sea-level trends are

660 observed for S3 to S5 relative to S1: sea level either declined (by 20 m during S3 and S5) or

661 hovered around a broad plateau (S4) (Fig. 7). Furthermore, sea-level histories are noticeably

662 different for the 5-6 kyr preceding S3 and S4 compared to S1 (this is the timeframe that

663 Grimm et al. (2015) suggest to be crucial for a deglaciation influence on sapropel deposition).

664 Falling sea level would have reduced the cross-sectional area of the Strait of Gibraltar and

665 Strait of Sicily, leading to reduced Atlantic-Mediterranean exchange, longer Mediterranean

666 residence times, and increased Mediterranean surface-water salinity in the more restricted and

667 highly evaporative basin (e.g., Rohling 1999; Rohling et al., 2014). The resultant increase in

668 surface density would have promoted deep-water formation rather than stagnation. Although 
670 after the main, rapid sea-level rise associated with termination II. It is hard to reconcile such

671 timings with timescales for deep-water stagnation based on deglaciation effects alone (see

672 below). For S3 and S4, sapropel onset coincides with peak rates of sea-level rise (Fig. 7c,d),

673 which may imply some degree of sea-level control on the timing of sapropel onset, in

674 addition to monsoon forcing.

675

676 To help clarify the processes leading to sapropel deposition, we can also consider general 677 trends in the LC21 $\delta^{13} \mathrm{C}$ records, together with previously published records from LC21

678 (Marino et al., 2007; Abu-Zied et al., 2008; Grelaud et al., 2012) which have now been 679 converted to the radiometrically-based chronology used here (Fig. 8). We focus on sapropel 680 onset and the prior 5-6 kyr because, as suggested by Grimm et al. (2015) for sapropel S1, at 681 least 5.5 or $6 \mathrm{kyr}$ (based on modelling and benthic $\delta^{13} \mathrm{C}$ data, respectively) of progressive 682 deep-water stagnation and oxygen consumption was required to initiate $\mathrm{S} 1$ deposition and 683 anoxia. There is no consistent trend among the LC21 $\delta^{13} \mathrm{C}$ profiles in the 5-6 kyrs preceding 684 sapropel onset (Fig. 8), implying that the processes necessary for sapropel deposition 685 (reduced ventilation, increased biological production) developed differently for each 686 sapropel. The most notable disparity is between S1 and S3-S5. For S1, the $\delta^{13} \mathrm{C}_{\text {rub-pac }}$ gradient 687 is minimal for most of the pre-sapropel period, and both $\delta^{13} \mathrm{C}_{\text {rub }}$ and $\delta^{13} \mathrm{C}_{\mathrm{pac}}$ start to decrease $688 \sim 2-3 \mathrm{kyr}$ before the $\mathrm{S} 1$ onset. This decline is mirrored in $\delta^{13} \mathrm{C}$ values for G. inflata (Fig. 8), a 689 planktonic foraminifer with a similar apparent ecological niche to N. pachyderma. In 690 contrast, prior to S3-S5 there is a 1-2\%o gradient between $\delta^{13} \mathrm{C}_{\mathrm{pac}}$ and $\delta^{13} \mathrm{C}_{\mathrm{rub}}$, and a negative 691 shift in both occurs much closer to sapropel onset, synchronous with a negative shift in the 692 LC21 residuals. For S3 and S4, these shifts also coincide with rising sea levels, so without 693 further proxy records it is difficult to conclusively distinguish between monsoon and 
694 deglaciation effects. However, the fact that $\delta^{13} \mathrm{C}$ trends prior to S3 and S4 are arguably more

695 similar to those pre-S5 than pre-S1, hints at a common development mechanism for S3, S4,

696 and S5.

697

698 The most extensive datasets in LC21 are for S1 and S5 (Fig. 8). These two sapropels have

699 already been studied extensively elsewhere (see Rohling et al., 2015, and references therein).

700 However, the advantage of our study is that we can now unambiguously examine timing

701 relationships between sea-level rise, monsoon run-off into the eastern Mediterranean, and key

702 proxy records, on an independent and chronologically consistent age-scale (Fig. 8).

703 Regarding S1, a spike in benthic foraminiferal abundances ('benthics/g') coincides with the

704 YD (Fig. 8a); abundances then decline until the S1 onset. This decline coincides with rapidly

705 rising sea levels, decreasing $\delta^{13} \mathrm{C}$ values, and a sharp increase in oxygen deficient species

706 (ODS) within the LC21 benthic foraminiferal assemblage (Abu-Zied et al., 2008; chronology

707 after Grant et al., 2012) (Fig. 8a). Importantly, the rise to peak monsoon run-off occurs after

708 the shift in benthic assemblages. This is compelling evidence for a key role of deglaciation in

709 instigating vertical stratification and deep-water anoxia prior to S1 formation. At the same

710 time, the synchronous onset of S1 and peak monsoon run-off into the eastern Mediterranean

711 is equally strong evidence that $\mathrm{S} 1$ deposition was tied to monsoon forcing.

712

713 In contrast, benthic fossils in core LC21 disappeared at the onset of (rather than prior to) sapropel S5 (Marino et al., 2007). Similar observations for S5 have been made previously.

715 For example, Schmiedl et al. (2003) studied a southeast Aegean core from a similar water

716 depth to LC21, and observed relatively high benthic foraminiferal abundances right up until

717 S5 onset. They concluded that bottom waters were sufficiently ventilated until the start of S5

718 deposition, despite an inferred stepwise reduction in oxygen content over the preceding $\sim 3$ 
kyr. Capotondi et al (2006) also found a close agreement between the onset of benthic anoxia and S5 deposition, and Jorissen (1999) noted differences in benthic foraminifera assemblages between S1 and S5. In LC21, the onset of benthic azoic conditions during S5 coincides with abrupt increases in organic carbon $\left(\mathrm{C}_{\text {org }}\right)$ deposition, isorenieratene concentrations, and abundances of Florisphaera profunda coccoliths (Grelaud et al., 2012), as well as with negative peaks in the $\delta^{13} \mathrm{C}$ and residuals records (Fig. 8d). The $\mathrm{C}_{\text {org }}$ increase is unlikely to be due solely to increased preservation, because the values are unusually high (up to 14\%) for Aegean sediments (cf typically 2-3\%; Mercone et al., 2001; Thomson et al., 2004). Elevated isorenieratene concentrations are indicative of anaerobic phototrophic Chlorobiaceae, while increased abundances of $F$. profunda are associated with an increase in subsurface rather than surface primary productivity. Together, these records point to the rapid development of a deep chlorophyll maximum and euxinic conditions at the onset of S5 in LC21 (Marino et al., 2007; Grelaud et al., 2012). Thus, for S5, there is a strong timing relationship between substantial monsoon run-off into the eastern Mediterranean, benthic anoxia, increased

733 (subsurface) productivity, and increased $\mathrm{C}_{\text {org }}$ deposition.

\subsection{African monsoon variability}

Our datasets, in line with previous studies based on less well constrained chronologies and/or

738 fewer sapropel events (Rohling et al., 2002, 2004; 2006; Emeis et al., 2003; Marino et al., 2007; De Lange et al., 2008; Hennekam et al., 2014), strongly suggest that the timing of monsoon run-off into the eastern Mediterranean was crucial in triggering surface buoyancy

741 changes necessary for sapropel deposition. Our results also show that the timing of this

742 monsoon run-off, relative to insolation changes, varied over the last glacial cycle (Fig. 7).

743 These timings were broadly similar for sapropels S1 and S5 (Fig. 7a,b) and for sapropels S3 
and S4 (Fig. 7c,d). Comparable phasings were observed among sea level-sapropel

745

746

747

748

749

750

751

752

753

754

755

756

757

758

759

760

761

762

763

764

765

766

767

768

relationships, whereby longer lags between insolation maxima and sapropel mid-points were observed for larger sea-level changes (Fig. 7; Table 2). These observations suggest that global ice-volume changes exceeding a certain magnitude interfere with the precessionpacing of the African monsoon.

An empirical link between African monsoon precipitation and glaciation has been inferred from model simulations. Freshwater hosing experiments for the North Atlantic suggest that the African monsoon weakened in response to (glacial) meltwater pulses (Chang et al., 2008; Tjallingii et al., 2008; Kageyama et al., 2013), due to atmosphere-ocean feedbacks associated with a reduced Atlantic meridional overturning circulation (AMOC) and a southward shift in the intertropical convergence zone (ITCZ) (Chang et al., 2008). Transient simulations (OttoBliesner et al., 2014) and a model set-up that included remnant ice sheets in addition to a North Atlantic freshwater influx (Lézine et al., 2011; Marzin et al., 2013) show similar results to the previous hosing experiments. Notably, Lézine et al. (2011) and Marzin et al. (2013) concluded that a freshwater flux into the North Atlantic would have had a larger impact on African monsoon precipitation than the presence of remnant ice sheets alone. This is in line with our observations: the magnitude of sea level rise (and therefore meltwater effects), rather than sea level at sapropel onset, distinguish the more insolation-lagged sapropels S1 and S5 (Section 4.2; Fig. 7).

A link between past African monsoon variability and global ice-volume changes appears to be supported by proxy data. For example, precession-scale variability in a West African monsoon proxy record was interpreted in terms of large-scale changes in global ice volume (Weldeab et al., 2007), while Heinrich Stadials (HS) have been invoked to explain millennial- 
scale dry periods in North Africa (Tjallingi et al., 2008), a delayed response of the East

770

771

772

773

774

775

776

777

778

779

780

781

782

783

784

785

786

787

788

789

790

791

792

793

African monsoon to precession/insolation forcing (Ziegler et al., 2010a), as well as a southward shift in the Sahara-Sahel boundary (Collins et al., 2013). In particular, Ziegler et al. (2010a) proposed that African monsoon intensity (and by inference, sapropel formation) varies in phase with northern hemisphere summer insolation but was suppressed during Heinrich-type cold events, possibly associated with periods of meltwater release and sea-level rise. This suppression led to an apparent lag of the African monsoon behind insolation maxima. Ziegler et al. (2010a) proposed that this lag - while variable - averaged 2-3 kyr between precession minima and African monsoon maxima/sapropel mid-points. Our results for the Holocene and Last Interglacial support this hypothesis: S1and S5 (and coeval increases in monsoon run-off) are preceded by North Atlantic cold events and meltwater pulses (dRSL>0) (Fig. 9a,b), and the mid-points of these sapropels lag maximum insolation by 2-3 kyr (Fig. 7a,b). However, the relationship between these phenomena is not consistent for all sapropels/monsoon intervals. Meltwater pulses and North Atlantic cold events C21 and C24 preceded intervals of monsoon run-off and sapropel deposition in the eastern Mediterranean during MIS 5a (sapropel S3) and 5c (sapropel S4), and cold event C23 interrupted S4 deposition (Fig. 9c,d), yet here the mid-point of these sapropels (and of the concurrent monsoon run-off intervals) is in direct phase with an insolation maximum. Hence, cold events and meltwater pulses do not necessarily induce a precession-lag in African monsoon /sapropel timing.

The maximum rates of sea-level rise prior to S3 are comparable to those for S5 (and for S1, if we consider the probabilistic dRSL records) (Fig. 9), implying that the rate of meltwater addition to the global ocean does not determine sapropel/monsoon lag. However, total sealevel change prior to S1 and S5 is tens of metres greater than for S3 and S4. If melting rates 
are comparable, this suggests that it is the duration of the meltwater addition that disrupts the

795

796

797

798

799

800

801

802

803

804

805

806

807

808

809

810

811

812

813

814

815

816

817

818 precession-pacing of the African monsoon. Calculating from the start of the meltwater addition ('maximum probability' dRSL>0) to the onset of monsoon run-off and sapropel deposition, we find meltwater durations of $7 \mathrm{kyr}$ (for S5), $2 \mathrm{kyr}$ (for S4) and $1.6 \mathrm{kyr}$ (for S3) (Fig. 7). For S1, the Stanford et al. (2011) dRSL curve suggests that the main period of meltwater addition to the global ocean began ca 16.5-17 ka BP (Fig. 7a). This is consistent with a more recent estimate of $16.5 \mathrm{ka} \mathrm{BP}$ for the start of the main phase of deglaciation, although the initial phase began earlier ( 20 ka BP) (Lambeck et al., 2014). Hence, the duration of meltwater addition prior to $\mathrm{S} 1$ was likely 6-9 kyr.

Modelling experiments suggest that the sensitivity of the AMOC and ITCZ (hence African monsoon precipitation) to meltwater pulses is greatest under full-glacial conditions (Ganopolski and Rahmstorf, 2001; Swingedouw et al., 2009; Zhang et al., 2015). Our African monsoon run-off reconstructions cover both glacial-inception and early interglacial periods, so it is unlikely that our observations primarily reflect climate-dependent sensitivities of the African monsoon. This gives further weight to our preferred interpretation that the duration of meltwater input to the global ocean was critical in determining the timing of the African monsoon response to insolation forcing. Interestingly, the inclusion of variable northern hemisphere ice sheets in transient model simulations of African monsoon variability (Ziegler et al., 2010b; Weber and Tuenter, 2011) produced zero phase lag in the precession band, in line with previous simulations based on stationary ice-sheets (Tuenter et al., 2005; Kutzbach et al., 2008). While Weber and Tuenter (2011) acknowledged that the crude resolution of ice sheets and ocean circulation, and lack of atmospheric mid-latitude dynamics in these transient models may undermine their reliability, these simulations are nonetheless quasi-consistent with our observations: we observe a tight phasing between sapropel mid-points (hence 
819 African monsoon intervals) and insolation maxima (= precession minima) in MIS 5a and 5c

820 (Fig. 7c,d; Table 2). The fact that this observed phasing is not systematic among successive

821 insolation maxima, may be the reason for model-data offsets if only 'average' phasings are

822 considered. For example, lag correlation analyses (Caley et al., 2010) of a proxy record for

823 African monsoon run-off into the eastern Mediterranean (Revel et al., 2010) revealed an 824 average insolation-lag of $0.7 \mathrm{kyr}$ for African monsoon maxima over the past $45 \mathrm{kyr}$, but a 825 longer lag when the Holocene monsoon maximum was considered alone. Thus, statistical 826 analyses may not capture the detail of monsoon-ice-volume phasings.

\section{Conclusions}

829

830 We have established independent (radiometric-based) datings for sapropels S1, S3, S4 and S5

831 in eastern Mediterranean core LC21, and show that, in detail, insolation-sapropel phasings

832 were not systematic through the last glacial cycle. This observation potentially has

833 implications for the application of an assumed 3-kyr lag between insolation

834 maxima/precession minima and sapropel mid-points, and hence for the astronomical

835 chronology of eastern Mediterranean sedimentary sequences. For instance, previous sapropel 836 mid-point ages established by a lagged orbital tuning may be up to $3 \mathrm{kyr}$ too young, in cases

837 where the mid-points should actually be in direct phase (zero lag) with insolation maxima.

838 However, it is unlikely that sapropel ages established by that method are too old. We suggest

839 that persistent meltwater discharge into the North Atlantic over several kyrs, such as during

840 glacial terminations, modified the timing of sapropel deposition via a delay in the timing of

841 African monsoon run-off into the eastern Mediterranean. We show that the onset of this

842 monsoon run-off and sapropel deposition was near-synchronous (within $0.5 \mathrm{kyr}$ ) for all

843 sapropels considered here, and conclude that monsoon forcing was important in instigating 
the formation of these sapropels; furthermore, for sapropels S3-S5, monsoon forcing was

845 probably more important than sea-level rise. However, it is likely that sea-level rise, and

846 attendant hydrographic changes, strongly contributed to sapropel S1 deposition. Thus,

847 deglaciation affected sapropel deposition directly (via changes in Mediterranean

848 hydrography) and indirectly (via the response of the African monsoon to meltwater pulses).

849 The fact that sapropel S1 was probably affected by both of the above mechanisms may

850 explain why it exhibits the longest insolation lag compared to S3 to S5. That in turn would

851 suggest that the 3-kyr lag assumption for sapropel tuning (which is based on S1) results in

852 overestimated insolation lags for many sapropels. In this context, our observations may

853 reconcile apparent model-data offsets with respect to the orbital pacing of the African

854 monsoon, by demonstrating that insolation-monsoon phasings varied with the magnitude of

855 meltwater pulses.

856

857 Finally, we conclude that deciphering the degree to which deep-water anoxia/sapropel

858 deposition can be attributed to either sea-level rise or African monsoon run-off remains

859 challenging, because both processes respond to boreal summer insolation, and both lead to a

860 loss of surface buoyancy in the eastern Mediterranean and an attendant reduction in deep-

861 water ventilation. This buoyancy sensitivity likely dates back to when the Mediterranean

862 basin first became semi-enclosed from the open ocean during the Middle Miocene, which

863 coincides with the first appearance of sapropels at $~ 15.4 \mathrm{Ma}$ (Taylforth et al., 2014). Detailed

864 process modelling of sapropels older than S1, and including the western Mediterranean basin,

865 will help to elucidate how changes in sea level, SST, and monsoon run-off each contributed

866 to Mediterranean palaeohydrography and sapropel formation.

867

868 Acknowledgments 
This work was supported by Australian Research Council Australian Laureate Fellowship

Klimadynamik und biogeochemische Prozesse im Golf von Tarent: Von regionalen

Proxyvariationen zu Klimazeitserien (UM). We thank two anonymous reviewers for their constructive comments.

\section{References}

Abouelmagd, A., Sultan, M., Milewski, A., Kehew, A.E., Sturchio, N.C., Soliman, F., Krishnamurthy, R.V., Cutrim, E., 2012. Toward a better understanding of palaeoclimatic regimes that recharged the fossil aquifers in North Africa: inferences

Affek, H.P., Bar-Matthews, M., Ayalon, A., Matthews, A., Eiler, J.M., 2008. from stable isotope and remote sensing data. Palaeogeography, Palaeoclimatology, Palaeoecology 329-330, 137-149.

Abouelmagd, A., Sultan, M., Sturchio, N.C., Soliman, F., Rashed, M., Ahmed, M., Kehew, A.E., Milewski, A., Chouinard, K., 2014. Paleoclimate record in the Nubian Sandstone Aquifer, Sinai Peninsula, Egypt. Quat. Sci. Rev. 81, 158-167.

Abu-Zied, R.H., Rohling, E.J., Jorissen, F.J., Fontanier, C., Casford, J.S.L. Cooke, S. 2008. Benthic foraminiferal response to changes in bottom water oxygenation and organic carbon flux in the eastern Mediterranean during LGM to Recent times. Marine Micropaleontology 67, 46-68.

Glacial/interglacial temperature variations in Soreq cave speleothems as recorded by 'clumped isotope' thermometry. Geochim. Cosmochim. Acta 72, 5351-5360.

Almogi-Labin, A., Bar-Matthews, M., Shriki, D., Kolosovsky, E., Paterne, M., Schilman, B., Ayalon, A., Aizenshtat, Z., Matthews, A., 2009. Climatic variability during the last w90 $\mathrm{ka}$ of the southern and northern Levantine basin as evident from marine records and speleothems. Quaternary Science Reviews 28, 2882-2896.

Álvares-Solas, J., Montoya, M., Ritz, C., Ramstein, G., Charbit, S., Dumas, C., Nisancioglu, K., Dokken, T., Ganopolski, A., 2011. Heinrich event 1: an example of dynamical icesheet reaction to oceanic changes. Clim. Past 7, 1297-1306, doi:10.5194/cp-7-12972011. 
900

901

902

903

904

905

906

907

908

909

910

911

912

913

914

915

916

917

918

919

920

921

922

923

924

925

926

927

928

929

930

931

932

Bahr, A., Arz, H.W., Lamy, F.,Wefer, G., 2006. Late glacial to Holocene paleoenvironmental evolution of the Black Sea, reconstructed with stable oxygen isotope records obtained on ostracod shells. Earth Planet. Sci. Lett. 241, 863-875.

Bahr, A., Lamy, F., Arz, H.W., Major, C., Kwiecien, O., Wefer, G., 2008. Abrupt changes of temperature and water chemistry in the late Pleistocene and early Holocene Black Sea. Geochem. Geophys. Geosyst. 9, Q01004. http://dx.doi.org/10.1029/2007GC001683.

Bar-Matthews, M., Ayalon, A., Gilmour, M., Matthews, A., Hawksesworth, C., 2003. Sealand oxygen isotopic relationships from planktonic foraminifera and speleothems in the Eastern Mediterranean region and their implication for paleorainfall during interglacial intervals. Geochim. Cosmochim. Acta 67, 3181-3199.

Baumgartner, M., Kindler, P., Eicher, O., Floch, G., Schilt, A., Schwander, J., Spahni, R., Capron, E., Chappellaz, J., Leuenberger, M., Fischer, H., Stocker, T.F., 2014. NGRIP $\mathrm{CH}_{4}$ concentration from 120 to $10 \mathrm{kyr}$ before present and its relation to a $\delta^{15} \mathrm{~N}$ temperature reconstruction from the same ice core. Clim. Past 10, 903-920, doi:10.5194/cp-10-903-2014.

Bazin, L., Landais, A., Lemieux-Dudon, B., Toyé Mahamadou Kele, H., Veres, D., Parrenin, F., Martinerie, P., Ritz, C., Capron, E., Lipenkov, V., Loutre, M.-F., Raynaud, D., Vinther, B., Svensson, A., Rasmussen, S. O., Severi, M., Blunier, T., Leuenberger, M., Fischer, H., Masson-Delmotte, V., Chappellaz, J., Wolff, E., 2013. An optimized multiproxy, multi-site Antarctic ice and gas orbital chronology (AICC2012): 120-800 ka. Clim. Past, 9, 1715-1731, doi:10.5194/cp-9-1715-2013.

Bianchi, D., Zavatarelli, M., Pinardi, N., Capozzi, R., Capotondi, L., Corselli, C., Masina, S. 2006. Simulations of ecosystem response during the sapropel S1 deposition event. Palaeogeogr., Palaeoclimatol., Palaeoecol. 235, 265-287.

Boch, R., Cheng, H., Spötl, C., Edwards, R.L., Wang, X., Häuselmann, Ph., 2011. NALPS: a precisely dated European climate record 120-60 ka. Clim. Past 7, 1247-1259, doi:10.5194/cp-7-1247-2011.

Bosmans, J.H.C., Drijfhout, S.S., Tuenter, E., Hilgen, F.J., Lourens, L.J., Rohling, E.J., 2015. Precession and obliquity forcing of the freshwater budget over the Mediterranean. Quat. Sci. Rev. 123, 16-30.

Bronk Ramsey, C., 2008. Deposition models for chronological records. Quat. Sci. Rev. 27, 42-60.

Bronk Ramsey, C., 2009. Bayesian analysis of radiocarbon dates. Radiocarbon 511, 337-360. 
933

934

935

936

937

938

939

940

941

942

943

944

945

946

947

948

949

950

951

952

953

954

955

956

957

958

959

960

961

962

963

964

965

Cacho, I., Grimalt, J.O., Pelejero, C., Canals, M., Sierro, F.J., Flores, J.A., Shackleton, N. 1999. Dansgaard-Oeschger and Heinrich event imprints in Alboran Sea paleotemperatures. Paleoceanography 14, 698-705.

Caley, T., Malaizé, B., Revel, M., Ducassou, E., Wainer, K., Ibrahim, M., Shoeaib, D., Migeon, S., Marieu, V. 2011. Orbital timing of the Indian, East Asian and African boreal monsoons and the concept of a 'global monsoon'. Quaternary Science Reviews 30, 3705-3715.

Capotondi, L., Principato, M.S., Morigi, C., Sangiorgi, F., Maffioli, P., Giunta, S., Negri, A., Corselli, C., 2006. Foraminiferal variations and stratigraphic implications to the deposition of sapropel S5 in the eastern Mediterranean. Palaeogeogr. Palaeoclimatol. Palaeoecol. 235, 48-65.

Casford, J.S.L., Rohling, E.J., Abu-Zied, R.H., Jorissen, F.J., Leng, M., Thomson, J. 2003. A dynamic concept for eastern Mediterranean circulation and oxygenation during sapropel formation. Palaeogeography, Palaeoclimatology, Palaeoecology 190, 103-119.

Casford, J.S.L., Abu-Zied, R., Rohling, E.J., Cooke, S., Fontanier, Ch., Leng, M., Millard, A., Thomson, J. 2007. A stratigraphically controlled multi-proxy chronostratigraphy for the eastern Mediterranean. Paleoceanography 22, PA4215, doi:10.1029/2007PA001422.

Chang, P., Zhang, R., Hazeleger, W., Wen, C., Wan, X., Ji, L., Haarsma, R.J., Breugem, W.P., Seidel, H., 2008. Oceanic link between abrupt changes in the North Atlantic Ocean and the African monsoon. Nature Geoscience 1 (7), 444-448.

Chappellaz, J., Barnola, J.M., Raynaud, D., Korotkevich, Y.S., Lorius, C., 1990. Ice-core record of atmospheric methane over the past 160,000 years. Nature 345, 127-131.

Cita, M.B., Vergnaud-Grazzini, C., Robert, C., Chamley, H., Ciaranfi, N., d'Onofrio, S., 1977. Paleoclimatic record of a long deep sea core from the eastern Mediterranean. Quat. Res. 8, 205-235.

Collins, J.A., Govin, A., Mulitza, S., Heslop, D., Zabel, M., Hartmann, J., Röhl, U., Wefer, G., 2013. Abrupt shifts of the Sahara-Sahel boundary during Heinrich stadials. Clim. Past 9, 1181-1191, doi:10.5194/cp-9-1181-2013.

Cramp, A., O’Sullivan, G., 1999. Neogene sapropels in the Mediterranean: a review. Mar. Geol. 153, 11-28.

De Lange, G.J., Thomson, J., Reitz, A., Slomp, C.P., Speranza Principato, M., Erba, E., Corselli, C. 2008. Synchronous basin-wide formation and redox-controlled preservation of a Mediterranean sapropel. Nature Geoscience 1, 606-610. 
966

967

968

969

970

971

972

973

974

975

976

977

978

979

980

981

982

983

984

985

986

987

988

989

990

991

992

993

994

995

996

997

998

Deschamps, P., Durand, N., Bard, E., Hamelin, B., Camoin, G., Thomas, A.L., Henderson, G., Okuno, J., Yokoyama, Y., 2012. Ice-sheet collapse and sea-level rise at the Bølling warming 14,600 years ago. Nature 483, 559-564.

Dymond, J., Suess, E., Lyle, M. 1992. Barium in deep-sea sediment: a geochemical proxy for paleoproductivity. Paleoceanography 7, 163-181.

Emeis, K.-C., Robertson, A.H.F., Richter, C., and shipboard scientific party. 1996. Proceedings of the Ocean Drilling Program, Initial Reports, Leg 160. College Station, Texas.

Emeis, K.C., Struck, U., Schulz, H.M., Bernasconi, S., Sakamoto, T., Martinez-Ruiz, F., 2000. Temperature and salinity of Mediterranean Sea surface waters over the last 16,000 years: constraints on the physical environment of S1 sapropel formation based on stable oxygen isotopes and alkenone unsaturation ratios. Palaeogeogr.

Palaeoclimatol. Palaeoecol. 158, 259-280.

Emeis, K.C., Schulz, H., Struck, U., Rossignol-Strick, M., Erlenkeuser, H., Howell, M.W., Kroon, D., Mackensen, H., Ishizuka, S., Oba, T., Sakamoto, T., Koizumi, I., 2003. Eastern Mediterranean surface water temperatures and $\delta 180$ composition during deposition of sapropels in the late Quaternary. Paleoceanography 18. http://dx.doi.org/10. 1029/2000PA000617.

Esssallami, L., Sicre, M.A., Kallel, N., Siani, G., 2007. Hydrological changes in the Mediterranean Sea over the last 30,000 years. Geochemistry, Geophysics, Geosystems $8,1-11$.

Frumkin, A., Bar-Yosef, O., Schwarzc, H.P., 2011. Possible paleohydrologic and paleoclimatic effects on hominin migration and occupation of the Levantine Middle Paleolithic. J. Human Evolution 60, 437-451.

Ganopolski, A., Rahmstorf, S., 2001. Rapid changes of glacial climate simulated in a coupled climate model. Nature 409, 153-158.

Gasse, F., 2000. Hydrological changes in the African tropics since the last glacial maximum. Quat. Sci. Rev. 19, 189-211.

Grant, K.M., Rohling, E.J., Bar-Matthews, Ayalon, A., Bronk Ramsey, C., M., Satow, C., Medina-Elizalde, M., Roberts, A.P. 2012. Rapid coupling between ice volume and polar temperature over the past 150,000 years. Nature 491, 744-747.

Grant, K.M., Rohling, E.J., Bronk Ramsey, C., Cheng, H., Edwards, R.L., Florindo, F., Heslop, D., Marra, F., Roberts, A.P., Tamisiea, M.E., Williams, F., 2014. Sea-level 
variability over five glacial cycles. Nature Commun. 5, 5076. http://dx.doi.org/10.1038/ncomms6076.

Grelaud, M., Marino, G., Ziveri, P., Rohling, E.J., 2012. Abrupt shoaling of the nutricline in response to massive freshwater flooding at the onset of the last interglacial sapropel event. Paleoceanography 27, PA3208. http://dx.doi.org/10.1029/2012PA002288.

Grimm, R., Maier-Reimer, E., Mikolajewicz, U., Schmiedl, G., Muller-Navarra, K., Adloff, F., Grant, K.M., Ziegler, M., Lourens, L.J., Emeis, K.C., 2015. Late glacial initiation of Holocene eastern Mediterranean sapropel formation. Nat. Commun. 6, DOI: 10.1038/ncomms8099.

Hayes, A., Kucera, M., Kallel, N., Sbaffi, L., Rohling, E.J., 2005. Glacial Mediterranean sea surface temperatures reconstructed from planktonic foraminiferal assemblages. Quaternary Science Reviews, 24, 999-1016.

Higgs, N.C., Thomson, J., Wilson, T.R.S., Croudace, I.W. 1994. Modification and complete removal of eastern Mediterranean sapropels by postdepositional oxidation. Geology 22, 423-426.

Hilgen, F.J., Lourens, L.J., Berger, A., Loutre, M.F. 1993. Evaluation of the astronomically calibrated time scale for the Late Pliocene and earliest Pleistocene. Paleoceanography $8,549-565$.

Hughes, P.D., Woodward, J.C., Gibbard, P.L. 2006. Quaternary glacial history of the Mediterranean mountains. Progress in Physical Geography 30, 334-364.

Hughes, P.D., Woodward, J.C. 2009. Glacial and periglacial environments. In: Woodward, J.C. (Ed.), The Physical Geography of the Mediterranean. Oxford University Press. ISBN: 978-0-19-926803-0, pp. 33-67.

Jimenez-Amat, P., Zahn, R., 2015. Offset timing of climate oscillations during the last two glacial-interglacial transitions connected with large-scale freshwater perturbation. Paleoceanography 30, doi:10.1002/2014PA002710.

Jorissen, F.J. 1999. Benthic foraminiferal successions across Late Quaternary Mediterranean sapropels. Marine Geology 153, 91-101.

Kageyama, M., Merkel, U., Otto-Bliesner, B., Prange, M., Abe-Ouchi, A., Lohmann, G., Ohgaito, R., Roche, D.M., Singarayer, J., Swingedouw, D., Zhang, X., 2013. Climatic impacts of fresh water hosing under Last Glacial Maximum conditions: a multi-model study. Clim. Past 9, 935-953, doi:10.5194/cp-9-935-2013. 
Kallel, N., Paterne, M., Duplessy, J.C., Vergnaud-Grazzini, C., Pujol, C., Labeyrie, L., Arnold, M., Fontugne, M., Pierre, C., 1997. Enhanced rainfall in the Mediterranean region during the last sapropel event. Oceanol. Acta 20, 697-712.

Kallel, N., Duplessy, J.C., Labeyrie, L., Fontugne, M., Paterne, M., Montacer, M., 2000. Mediterranean pluvial periods and sapropel formation over the last 200000 years. Palaeogeogr. Palaeoclimatol. Palaeoecol. 157, 45-58.

Kandiano, E.S., Bauch, H.A., Fahl, K. 2014. Last interglacial surface water structure in the high latitudes. Global and Planetary Change 123, 67-76.

Kindler, P., Guillevic, M., Baumgartner, M., Schwander, J., Landais, A., Leuenberger., M. 2014. Temperature reconstruction from 10 to $120 \mathrm{kyr}$ b2k from the NGRIP ice core. Clim. Past, 10, 887-902, doi:10.5194/cp-10-887-2014.

Kolodny, Y., Stein, M., Machlus, M., 2005. Sea-rain-lake relation in the Last Glacial East Mediterranean revealed by $\delta 18 \mathrm{O}-\delta 13 \mathrm{C}$ in Lake Lisan aragonites. Geochim. Cosmochim. Acta 69, 4045-4060.

Kullenberg, B., 1952. On the salinity of the water contained in marine sediments. Medd. Oceanogr. Inst. Göteb. 21, 1-38.

Kutzbach, J.E., Liu, X., Liu, Z., Chen, G. 2008. Simulation of the evolutionary response of global summer monsoons to orbital forcing over the past 280,000 years. Climate Dynamics 30, 567-579.

Lambeck, K., Rouby, H., Purcell, A., Sun, Y., Sambridge, M., 2014. Sea level and global ice volumes from the Last Glacial Maximum to the Holocene. Proc. Natl. Academy. Sci., doi/10.1073/pnas.1411762111.

Langgut, D., Almogi-Labin, A., Bar-Matthews, M., Weinstein-Evron, M. 2011. Vegetation and climate changes in the South Eastern Mediterranean during the Last GlacialInterglacial cycle (86 ka): new marine pollen record. Quaternary Science Reviews 30, 3960-3972.

Larrasoaña, J.C., Roberts, A.P., Rohling, E.J., Winklhofer, M., Wehausen, R. 2003. Three million years of monsoon variability over the northern Sahara. Climate Dynamics 21, 689-698.

Laskar, J., 1990. The chaotic motion of the solar system: A numerical estimate of the size of the chaotic zones, Icarus, 88, 266-291. 
1063

1064

1065

1066

1067

1068

1069

1070

1071

1072

1073

1074

1075

1076

1077

1078

1079

1080

1081

1082

1083

1084

1085

1086

1087

1088

1089

1090

1091

1092

1093

1094

Lézine, A.-M., Hély, C., Grenier, C., Braconnot, P., Krinner, G., 2011. Sahara and Sahel vulnerability to climate changes, lessons from Holocene hydrological data. QSR 30, 3001-3012.

Lombo Tombo, S., Dennielou, B., Berné, S., Bassetti, M.-A., Toucanne, S., Jorry, S.J., Jouet, G., Fontanier, C. 2015. Sea-level control on turbidite activity in the Rhone canyon and the upper fan during the Last Glacial Maximum and Early deglacial. Sediment. Geol. 323, 148-166.

Lourens, L.J., Antonarakou, A., Hilgen, F.J., van Hoof, A.A.M., Vergnaud-Grazzini, C.,Zachariasse, W.J. 1996. Evaluation of the Plio-Pleistocene astronomical timescale. Paleoceanography 11, 391-413.

Lourens, L.J., Hilgen, F., Shackleton, N. J., Laskar, J., Wilson, D. 2004. The Neogene Period. In: Gradstein, F. M., Ogg, J. G., Smith, A. G. (eds) A Geologic Timescale 2004, Cambridge University Press, 409-440.

Major, C.O., Goldstein, S.L., Ryan, W.B.F., Lericolais, G., Piotrowski, A.M., Hajdas, I. 2006. The co-evolution of Black Sea level and composition through the last deglaciation and its paleoclimatic significance. Quat. Sci. Rev. 25, 2031-2047.

Marino, G., Rohling, E.J., Rijpstra, W.I., Sangiorgi, F., Schouten, S., Sinninghe Damsté, J.S. 2007. Aegean Sea as driver for hydrological and ecological changes in the eastern Mediterranean. Geology 35, 675-678.

Marino, G., Rohling, E.J., Sangiorgi, F., Hayes, A., Casford, J.S.L., Lotter, A.F., Kucera, M., Brinkhuis, H. 2009. Early and middle Holocene in the Aegean Sea: interplaybetween high and low latitude climate variability. Quaternary Science Reviews 28, 3246-3262.

Marino, G., Rohling, E.J., Rodríguez-Sanz, L., Grant, K.M., Heslop, D., Roberts, A.P., Stanford, J.D., Yu, J., 2015. Bipolar seesaw control on last interglacial sea level. Nature $522,197-201$.

Marzin, C., Braconnot. P., Kageyama, M., 2013. Impact of a meltwater flux and of the remnant ice sheet monsoons at $9.5 \mathrm{kyr}$ BP. Geophysical Research Letters

Matthews, A., Ayalon, A., Bar-Matthews, M., 2000. D/H ratios of fluid inclusions of Soreq Cave (Israel) speleothems as a guide to the Eastern Mediterranean Meteoric Line relationships in the last $120 \mathrm{ky}$. Chem. Geol. 166, 183-191.

McGarry, S., Bar-Matthews, M., Matthews, A., Vaks, A., Schilman, B., Ayalon, A., 2004. Constraints on hydrological and paleotemperature variations in the Eastern 
Mediterranean region in the last 140 ka given by the $\delta \mathrm{D}$ values of speleothem fluid inclusions. Quat. Sci. Rev. 23, 919-934.

McManus, J. F., Bond, G. C., Broecker, W. S., Johnsen, S., Labeyrie, L., Higgins, S., 1994. High-resolution climate records from the N. Atlantic during the last interglacial. Nature 371, 326-329.

Melki, T., Kallel, N., Jorissen, F.J., Guichard, JF., Dennielou, B., Berné, S., Labeyrie, L., Fontugne, M. 2009. Abrupt climate change, sea surface salinity and paleoproductivity in the western Mediterranean Sea (Gulf of Lion) during the last $28 \mathrm{kyr}$. Palaeogeography, Palaeoclimatology, Palaeoecology 279, 96-113.

Mercone, D., Thomson, J., R.H., Croudace, I.W., Siani, G., Paterne, M., Troelstra, S. 2000. Duration of S1, the most recent Mediterranean sapropel, as indicated by AMS radiocarbon and geochemical evidence. paleoceanography 15, 336-347.

Mercone, D., Thomson, J., Abu-Zied, R.H., Croudace, I.W., Rohling, E.J. 2001. Highresolution geochemical and micropalaeontological profiling of the most recent eastern Mediterranean sapropel. Marine Geology 177, 25-44.

Milner, A.M., Collier, R.E.L., Roucoux, K.H., Müller, U.C., Pross, J., Kalaitzidis, S., Christanis, K., Tzedakis, P.C., 2012. Enhanced seasonality of precipitation in the Mediterranean during the early part of the Last Interglacial. Geology 40, 919-922.

Nicholson, S.E., 2009. A revised picture of the structure of the "monsoon'” and land ITCZ over West Africa. Clim. Dyn. 32, 1155-1171, DOI 10.1007/s00382-008-0514-3.

Nijenhuis, I.A., Bosch, H.J., Sinnighe Damsté, J.S., Brumsack, H.-J., de Lange, G.J. 1999. Organic matter and trace element rich sapropels and black shales: a geochemical comparison. Earth and Planetary Science Letters 169, 277-290.

Olausson, E., 1961. Studies of deep-sea cores. Reports of the Swedish Deep Sea Expedition 1947-1948 8, pp. 353-391.

Osborne, A.H., Vance, D., Rohling, E.J., Barton, N., Rogerson, M., Fello, N. 2008. A humid

Osborne, A., Marino, G., Vance, D., Rohling, E.J. 2010. Eastern Mediterranean surface water Nd during Eemian sapropel S5: monitoring northerly (mid latitude) versus southerly (sub tropical) freshwater contributions. Quaternary Science Reviews 29, 2473-2483.

Otto-Bliesner, B.L., Russell, J.M., Clark, P.U., Liu, Z., Overpeck, J.T., Konecky, B., deMenocal, P., Nicholson, S.E., He, F., Lu, Z., 2014. Coherent changes of southeastern 
equatorial and northern African rainfall during the last deglaciation. Science 346, $1223-1227$.

1131 Pinardi, N., Bonaduce, A., Navarra, A., Dobricic, S., Oddo, P., 2014. The Mean Sea Level 1132 Equation and Its Application to the Mediterranean Sea. Journal of Climate 27, 442-447. 1133 Rasmussen, S.O., Bigler, M., Blockley, S.P., Blunier, T., Buchardt, S.L., Clausen, H.B., stratigraphic framework for abrupt climatic changes during the Last Glacial period based on three synchronized Greenland ice-core records: refining and extending the INTIMATE event stratigraphy. Quaternary Science Reviews, 106, pp.14-28.

Revel, M., Ducassou, E., Grousset, F.E., Bernasconi, S.M., Migeon, S., Revillon, S., Mascle, J., Murat, A., Zaragosi, S., Bosch, D., 2010. 100,000 years of African monsoon variability recorded in sediments of the Nile margin. Quat. Sci. Rev. 29, 1342-1362.

Rogerson, M., Colmenero-Hidalgo, E., Levine, R.C., Rohling, E.J., Voelker, A.H.L., Bigg, G.R., Schönfeld, J., Cacho, I., Sierro, F.J., Löwemark, L., Reguera, M.I., deAbreu, L., Garrick, K., 2010. Enhanced Mediterranean-Atlantic exchange during Atlantic freshening phases. Geochem. Geophys. Geosyst. 11:Q08013. doi:08010.01029/02009GC002931.

Rohling, E.J., 1994. Review and new aspects concerning the formation of Mediterranean sapropels. Marine Geology 122, 1-28.

Rohling, E.J. 1999. Environmental control on Mediterranean salinity and $\delta^{18} \mathrm{O}$. Paleoceanography 14, 706-715.

Rohling, E.J., 2013. Quantitative assessment of glacial fluctuations in the level of Lake Lisan, Dead Sea rift. Quaternary Science Reviews 70, 63-72.

Rohling, E.J., Gieskes, W.W.C., 1989. Late Quaternary changes in Mediterranean Intermediate Water density and formation rate. Paleoceanography 4, 531-545.

Rohling, E.J., Bryden, H.L., 1994. Estimating past changes in the eastern Mediterranean freshwater budget, using reconstructions of sea level and hydrography. Proc. K. Ned. Akad. Wet. Ser. B 97, 201-217

Rohling, E.J., De Rijk. S. 1999. The Holocene climate optimum and last glacial maximum in the Mediterranean: the marine oxygen isotope record. Marine Geology 153, 57-75.

Rohling, E.J., Cane, T.R., Cooke, S., Sprovieri, M., Bouloubassi, I., Emeis, K.C., Schiebel, R., Kroon, D., Jorissen, F.J., Lorre, A., Kemp, A.E.S., 2002. African monsoon 

75.

Rohling, E.J., Sprovieri, M., Cane, T.R., Casford, J.S.L., Cooke, S., Bouloubassi, I., Emeis, K.C., Schiebel, R., Hayes, A., Jorissen, F.J., Kroon, D., 2004. Reconstructing past planktic foraminiferal habitats using stable isotope data: a case history for Mediterranean sapropel S5. Mar. Micropaleontol. 50, 89-123.

Rohling, E.J., Hopmans, E.C., Sinninghe-Damsté, J.S., 2006.Water column dynamics during the last interglacial anoxic event in the Mediterranean (sapropel S5). Paleoceanography 21, PA2018. http://dx.doi.org/10.1029/2005PA001237.

Rohling, E.J., Grant, K., Bolshaw, M., Roberts, A.P., Siddall, M., Hemleben, Ch., Kucera, M., 2009. Antarctic temperature and global sea level closely coupled over the past five glacial cycles. Nature Geoscience 2, 500-504.

Rohling, E.J., Foster, G.L., Grant, K.M., Marino, G., Roberts, A.P., Tamisiea, M.E.,Williams, F., 2014. Sea-level and deep-sea-temperature variability over the past 5.3 million years. Nature 508, 477-482.

Rohling, E.J., Marino, G., Grant, K., 2015. Mediterranean climate and oceanography, and the periodic development of anoxic events (sapropels). Earth-Sci. Rev. 143, 62-97.

Rossignol-Strick, M., 1985. Mediterranean quaternary sapropels, an immediate response of the African monsoon to variation of insolation. Palaeogeography, Palaeoclimatology, Palaeoecology 49, 237-263.

Rossignol-Strick, M. 1987. Rainy periods and bottom water stagnation initiating brine accumulation and metal concentrations: 1. the Late Quaternary. Paleoceanography 2, 333-360,

Rossignol-Strick, M. 1999. The Holocene climatic optimum and pollen records of sapropel 1 in the eastern Mediterranean, 9000-6000 BP. Quaternary Science Reviews 18, 515-

Rossignol-Strick, M., Paterne, M. 1999. A synthetic pollen record of the eastern Mediterranean sapropels of the last $1 \mathrm{Ma}$ implications for the time-scale and formation of sapropels. Marine Geology 153, 221-237.

Rossignol-Strick, M., Nesteroff, W., Olive, P., Vergnaud-Grazzini, C. 1982. After the deluge, Mediterranean stagnation and sapropel formation. Nature 295, 105-110. 
1192

1193

1194

1195

1196

1197

1198

1199

1200

1201

1202

1203

1204

1205

1206

1207

1208

1209

1210

1211

1212

1213

1214

1215

1216

1217

1218

1219

1220

1221

1222

1223

1224

1225

Ryan, W. B. F., 1972. Stratigraphy of Late Quaternary sediments in the Eastern Mediterranean. In Stanley, D. J., (Ed.), The Mediterranean Sea Strasbourg, Va. (Dowden, Hutchinson and Ross), p. 765.

Satow, C., Tomlinson, E.L., Grant, K.M., Albert, P.G., Smith, V.C., Manning, C.J., Ottolini, L., Wulf, S., Rohling, E.J., h, Lowe, J.J., Blockley, S.P.E., Menzies, M.A., 2015. A new contribution to the Late Quaternary tephrostratigraphy of the Mediterranean: Aegean Sea core LC21. Quat. Sci. Rev. 117, 96-112.

Schilt, A., Buiron, D., Capron, E., Chappellaz, J., Loulergue, L., Spahni, R., Stocker, T.F. 2010. EPCIA Dronning Maud Land ice core $\mathrm{CH}_{4}$ data to $140 \mathrm{kyr}$ BP. IGBP PAGES/World Data Center for Paleoclimatology Data Contribution Series \# 2010-131. NOAA/NCDC Paleoclimatology Program, Boulder CO, USA.

Schmiedl, G., Mitschele, A., Beck, S., Emeis, K.C., Hemleben, Ch., Schultz, H., Sperling, M., Weldeab, S., 2003. Benthic foraminiferal record of ecosystemvariability in the eastern Mediterranean Sea during times of sapropel S5 and S6 deposition. Palaeogeogr. Palaeoclimatol. Palaeoecol. 190, 139-164.

Scrivner, A.E., Vance, D., Rohling, E.J., 2004. New neodymium isotope data quantify Nile involvement in Mediterranean anoxic episodes. Geology 32, 565-568.

Siddall, M., Rohling, E.J., Almogi-Labin, A., Hemleben, Ch., Meischner, D., Schmeltzer, I., Smeed, D.A. 2003. Sea-level fluctuations during the last glacial cycle. Nature 423, 853858.

Siddall, M., Smeed, D.A., Hemleben, Ch., Rohling, E.J., Schmeltzer, I., Peltier, W.R. 2004. Understanding the Red Sea response to sea level. Earth and Planetary Science Letters $225,421-434$.

Sierro, F.J., Hodell, D.A., Curtis, J.H., Flores, J.A., Reguera, I., Colmenero-Hidagalo, E., Barcena, M.A., Grimalt, J.O., Cacho, I., Frigola, J., Canals, M. 2005. Impact of iceberg melting on Mediterranean thermohaline circulation during Heinrich events. Paleoceanography 20, 1-13.

Soulet, G., Ménot, G., Bayon, G., Rostek, F., Ponzevera, E., Toucanne, S., Lericolais, G., Bard, E., 2013. Abrupt drainage cycles of the Fennoscandian Ice Sheet. Proc. Natl. Academy Sci. 110, 6682-6687.

Spahni, R., Wania, R., Neef, L., van Weele, M., Pison, I., Bousquet, P., Frankenberg, C., Foster, P. N., Joos, F., Prentice, I. C., van Velthoven, P., 2011. Constraining global methane emissions and uptake by ecosystems. Biogeosciences, 8, 1643-1665, doi:10.5194/bg-8-1643-2011. 
Sperling, M., Schmiedl, G., Hemleben, Ch., Emeis, K.C., Erlenkeuser, H., Grootes, P.M., 2003. Black Sea impact on the formation of eastern Mediterranean sapropel S1? Evidence from the Marmara Sea. Palaeogeogr. Palaeoclimatol. Palaeoecol. 190, 9-21. Stanford, J.D., Hemingway, R., Rohling, E.J., Challenor, P.G., Medina-Elizalde, M., Lester, A.J., 2011. Sea-level probability for the last deglaciation: a statistical analysis of farfield records. Global and Planetary Change 79, 193-203.

Swingedouw, D., Mignot, J., Braconnot, P., Mosquet, E., Kageyama, M., Alkama, R., 2009. Impact of freshwater release in the North Atlantic under different climate conditions in an OAGCM. Journal of Climate 22, 6377-6403.

Swingedouw, D, Rodehacke, CB, Behrens, E, Menary, M, Olsen, SM, Gao, Y, Mikolajewicz, U, Mignot, J, and Biastoch, A (2013). Decadal fingerprints of freshwater discharge around Greenland in a multi-model ensemble Climate Dynamics, 41(3-4):695-720.

Taylforth, J.E., McCay, G.A., Ellam, R., Raffi, I., Kroon, D., Robertson, A.H.F. 2014. Middle Miocene (Langhian) sapropel formation in the easternmost Mediterranean deepwater basin: Evidence from northern Cyprus. Marine and Petroleum Geology 57, 521536.

Thomson, J., Higgs, N.C., Wilson, T.R.S., Croudace, I.W., De Lange, G.J., van Santvoort, P.J.M. 1995. Redistribution and geochemical behaviour of redox sensitive elements around S1, the most recent Eastern Mediterranean sapropel. Geochimica et Cosmochimica Acta 59, 3487-3501.

Thomson. G., Mercone, D., de Lange, G.J., van Santvoort, P.J.M. 1999. Review of recent advances in the interpretation of Eastern Mediterranean sapropel S1 from geochemical evidence. Marine Geology 153, 77-89.

Thomson, J., Crudeli, D., De Lange, G.J., Slomp, C.P., Erba, E., Corselli, C., Calvert, S.E., 2004. Florisphaera profunda and the origin and diagenesis of carbonate phases in eastern Mediterranean sapropel units. Paleoceanography 19, PA3003. http://dx.doi.org/10. 1029/2003PA000976.

Tjallingii, R., Claussen, M., Stuut, J.-B.W., Fohlmeister, J., Jahn, A., Bickert, T., Lamy, F., Rohl, U., 2008. Coherent high- and low-latitude control of the northwest African hydrological balance. Nature Geoscience 1, 670-675.

Toucanne, S., Soulet, G., Freslon, N., Silva Jacinto, R., Dennielou, B., Zaragosi, S., Eynaud, F., Bourillet, J.-F., Bayon, G. 2015a. Millennial-scale fluctuations of the European Ice 
Sheet at the end of the last glacial, and their potential impact on global climate. Quaternary Science Reviews 123, 113-133.

1260 Toucanne, S., Minto'o, C.M.A., Fontanier, C., Bassetti, M.A., Jorry, S.J., Jouet, G., $2015 b$.

1261 Tracking rainfall in the northern Mediterranean borderlands during sapropel deposition.

1262 Quaternary Science Reviews 129, 178-195.

1263 Troelstra, S.R., Ganssen, G.M., Van der Borg, K., De Jong, A.F.M., 1991. A Late Quaternary stratigraphic framework for eastern Mediterranean sapropel S1 based on AMS ${ }^{14} \mathrm{C}$ dates and stable isotopes. Radiocarbon, 33: 15-21.

Tuenter, E., Weber, S.L., Hilgen, F.J., Lourens, L.J., Ganopolski, A. 2005. Simulation of climate phase lags in response to precession and obliquity forcing and the role of vegetation. Climate Dynamics 24, 279-295.

Tzedakis, P.C., 2007. Seven ambiguities in the Mediterranean palaeoenvironmental narrative. Quat. Sci. Rev. 26, 2042-2066.

Tzedakis, P.C., 2009. Cenozoic climate and vegetation change. In: Woodward, J.C. (Ed.), The Physical Geography of the Mediterranean. Oxford University Press, Oxford, pp. 89-137.

Tzedakis, P.C., Lawson, I.T., Frogley, M.R., Hewitt, G.M., Preece, R.C. 2002. Buffered vegetation changes in a Quaternary refugium: evolutionary implications. Science 297, 2044-2047.

Tzedakis, P.C., Frogley, M.R., Heaton, T.H.E. 2003. Last interglacial conditions in southern Europe: evidence from Ioannina, northwest Greece. Global and Planetary Change 36, 157-170.

Vaks, A., Bar-Matthews, M., Ayalon, A., Matthews, A., Frumkin, A., Dayan, U., Halicz, L., Almogi-Laban, A., Schilman, B. 2006. Paleoclimate and location of the border between Mediterranean climate region and the Saharo-Arabian Desert as revealed by speleothems from the northern Negev Desert, Israel. Earth and Planetary Science Letters 249, 384-399.Voelker, A.H.L., Lebreiro, S.M., Schöfeld, J., Cacho, I., Erlenkeuser, H., Abrantes, F., 2006. Mediterranean outflow strengthening during northern hemisphere coolings: a salt source for the glacial Atlantic? Earth and Planetary Science Letters 245, 39-55.

Weber, S.L., Tuenter, E. 2011. The impact of varying ice sheets and greenhouse gases on the intensity and timing of boreal summer monsoons. Quaternary Science Reviews 30, 469479. 
1291 Weldeab, S., Lea, D.W., Schneider, R.R., Andersen, N., 2007. 155,000 years of West African monsoon and ocean thermal evolution. Science 316, 1303-1307.

1293 Wijmstra, T.A., Young, R., Witte, H.J.L. 1990. An evaluation of the climatic conditions 1294 during the Late Quaternary in northern Greece by means of multivariate analysis of palynological data and comparison with recent phytosociological and climatic data. Geologie en Mijnbouw 69, 243-251.

1297 Zhang, X., Prange, M., Merkel, U., Schulz, M., 2015. Spatial fingerprint and magnitude of changes in the Atlantic meridional overturning circulation during marine isotope stage 3. Geophys. Res. Lett., 42, 1903-1911, doi:10.1002/2014GL063003.

1300 Ziegler, M., Tuenter, E., Lourens, L.J. 2010a. The precession phase of the boreal summer monsoon as viewed from the eastern Mediterranean (ODP Site 968). Quaternary Science Reviews 29, 1481-1490.

1303 Ziegler, M., Lourens, L.J., Tuenter, E., Hilgen, F.J., Reichart, G.J., Weber, S.L. 2010b. Precession phase offset between Arabian Sea biological productivity and the Indian summer monsoon. Paleoceanography 25, PA3213, doi:10.1029/2009PA001884. 


\section{Table 1}

Age boundaries, duration [kyr, in parentheses] and mid-point of core LC21 sapropels, and timing of the respective monsoon signal.

\begin{tabular}{lcccc}
\hline & $\begin{array}{c}\text { Age: } \\
(\mathrm{ka} \mathrm{BP})\end{array}$ & Sapropel & $\begin{array}{c}\text { Sapropel } \\
\text { mid-point }\end{array}$ & $\begin{array}{c}\text { Monsoon } \\
\text { onset }\end{array}$ \\
\hline S1 & $6.1-10.5$ & {$[4.4]$} & 8.3 & 10.8 \\
S3 & $80.8-85.8$ & {$[5.0]$} & 83.3 & 85.8 \\
S4 & $101.8-107.8$ & {$[6.0]$} & 104.8 & 108.0 \\
S4 interruption & $104.0-105.4$ & {$[1.4]$} & 104.9 & \\
S5 & $121.5-128.3$ & {$[6.8]$} & 124.9 & 128.3 \\
\hline
\end{tabular}

Table 2

Lag between sapropel mid-points/onset and maxima in June-July insolation at $65^{\circ} \mathrm{N}$ (INSOL MAX $_{\text {, maxima in the summer inter-tropical insolation gradient (SITIG }}$ MAX), and precession minima $\left(\mathrm{P}_{\mathrm{MIN}}\right)$. Negative values mean that sapropel mid-points/onset lead the equivalent insolation maxima/precession minima. Red text denotes phase offsets $>2 \mathrm{kyr}$.

\begin{tabular}{lcccccc}
\hline $\begin{array}{c}\text { Phase: } \\
(\mathrm{kyr})\end{array}$ & \multicolumn{2}{c}{ Insolation:Sapropel } \\
MID & \multicolumn{3}{c}{ Insolation:Sapropel $_{\text {ONSET }}$} \\
\hline S1 & 2.5 & 2.8 & 3.3 & 0.3 & 0.6 & 1.1 \\
S3 & 0.1 & 0.8 & -0.3 & -2.4 & -1.7 & -2.8 \\
S4 & -0.5 & -0.2 & 0.7 & -3.6 & -3.2 & -2.3 \\
S5 & 2.1 & 2.6 & 2.1 & -1.3 & -0.8 & -1.3 \\
\hline
\end{tabular}




\section{Figure captions}

Figure 1 Location of marine cores discussed in the study and schematic of surface circulation in the eastern Mediterranean Sea.

Figure 2 Photograph of core LC21 (in metres below sea floor, mbsf) with scanning XRF records of barium and vanadium (grey, with 41-point moving averages in black). Sapropels are indicated (grey rectangles).

Figure 3 a) Planktonic foraminiferal (G. ruber) $\delta^{18} \mathrm{O}$ record from core LC21 (red), superimposed on a maximum probability sea-level record (Grant et al., 2012, 2014, based on the Red Sea sea-level reconstruction method of Siddall et al., 2003, 2004 and Rohling et al., 2009) which has been converted into equivalent Mediterranean $\delta^{18} \mathrm{O}$ values following Rohling et al. (2014) (darker blue shading $=68 \%$ confidence limits; lighter blue shading $=$ 95\% confidence limits). The RSL record is unreliable ca 14-23 ka BP so the probabilistic sealevel reconstruction of Stanford et al. (2011), (which is based on radiometrically dated sealevel indicators), has also been converted into equivalent Mediterranean $\delta^{18} \mathrm{O}$ values (black dashed lines $=2 \sigma$ error). b) $\mathrm{LC} 21 \delta^{18} \mathrm{O}$ 'residuals' beyond the $68 \%$ (pale red) and $95 \%$ (dark red) confidence limits of the Red Sea sea-level equivalent $\delta^{18} \mathrm{O}$ variations, and beyond the 95\% (black line) confidence limits of the Stanford et al. (2011) sea-level equivalent $\delta^{18} \mathrm{O}$ variations. A potential correlation between negative residuals and Heinrich Stadials (HS) 3 and 5 is based on the timing of Dansgaard-Oeschger stadials in Greenland ice (Rasmussen et al. 2014). Boreal summer insolation at $65^{\circ} \mathrm{N}$ (orange; after Laskar, 1990) is also shown. c) Maximum probability record of rates of sea-level change (dRSL) with its 95\% probability interval (blue envelope; equivalent to $2 \sigma$ ) (Grant et al., 2012, 2014), based on the Red Sea sea-level reconstruction method (Siddall et al., 2003, 2004; Rohling et al., 2009). The record is unreliable ca 14-23 ka BP so meltwater pulse 1A (Deschamps et al., 2012) is also indicated (blue square with $2 \sigma$ error bars), as well as Stanford et al.'s (2011) record of sea-level change rates (grey shading $=95 \%$ probability interval). The timing of sapropels S1-S5 (grey rectangles), the Younger Dryas (Rasmussen et al., 2014) and Heinrich Stadials 1 (ÁlvaresSolas et al., 2011) and 11 (Marino et al., 2015) (green rectangles), and an inferred sharp increase in monsoon run-off into the eastern Mediterranean (yellow lines) are also indicated. 
Figure 4 Stable oxygen isotope records through sapropel S5 of a) N. pachyderma from core LC21 (red) and ODP Site 975 (black; Marino et al., 2015), on the radiometrically constrained chronology of Grant et al. (2012), and b) N. pachyderma (black; Marino et al., 2015), Globigerinoides bulloides (orange), and G. ruber (blue) (Kandiano et al., 2014) from ODP Site 975. The timing of Heinrich Stadial 11 (Marino et al., 2015) is also indicated (green rectangle).

Figure 5 Ice-core methane $\left(\mathrm{CH}_{4}\right)$ variations from Greenland (NGRIP; Baumgartner et al., 2014) (a, c, d) and from Antarctica (EDML; Schilt et al., 2010) on the AICC2012 chronology (Bazin et al., 2013) (b), compared with LC21 residuals beyond the 68\% (orange) and $95 \%$ (red) confidence limits of sea-level equivalent $\delta^{18} \mathrm{O}$ variations. In (a), LC21 residuals are also calculated using the Stanford et al. (2011) sea-level reconstruction (open red circles) (see Fig. 3). The NGRIP temperature record is also in a and $\mathbf{d}$ (black; Kindler et al., 2014) and a U/Thdated speleothem $\delta^{18} \mathrm{O}$ record (brown) from the northern European Alps (NALPS; Boch et al., 2011) is shown in d. Intervals shown are for full interglacial conditions (a, b) and periods of glacial inceptions $(\mathbf{c}, \mathbf{d})$. Previously published sea-surface temperature (SST) records from LC21 (blue) were derived from alkenones (b; Marino et al., 2007) and from planktonic foraminiferal data (a; Marino et al., 2009), and have been converted to the Grant et al. (2012) chronology used here.

Figure 6 a) Soreq cave speleothem $\delta^{18} \mathrm{O}$ (red; Grant et al., 2012) and LC21 G. ruber $\delta^{18} \mathrm{O}$ (blue). b) Soreq cave 'excess' $\delta^{18} \mathrm{O}\left(\delta^{18} \mathrm{O}_{\text {SOREQ Xs }}\right)$ after removal of source-water $\delta^{18} \mathrm{O}$ signal (green; see section 3.3.2) for sapropels S1, S3, S4 and S5 (grey rectangles).

Figure 7 Ice-volume and insolation changes spanning sapropel intervals under full interglacial conditions (a, b) and periods of glacial inceptions (c, d). Maximum probability curves of relative sea-level (RSL, blue) and its rates of change (dRSL, black) with their 95\% probability intervals (paler envelopes; equivalent to $2 \sigma$ ) (Grant et al., 2012, 2014) are based on the Red Sea sea-level reconstruction method (Siddall et al., 2003, 2004; Rohling et al., 2009). The 95\% confidence intervals for all RSL data (blue dashed lines) are also shown. The Red Sea RSL and dRSL data are unreliable ca 14-23 ka BP so in (a) we also show Stanford et al.'s (2011) 95\% probability intervals of sea level and sea-level change rates (grey shading), as well as meltwater pulse 1A (Deschamps et al., 2012). Insolation curves are for boreal 
summer at $65^{\circ} \mathrm{N}$ (red) and the summer inter-tropical insolation gradient (SITIG; green) (based on Laskar, 1990), with filled circles indicating maxima. Sapropels (grey rectangles) and an inferred sharp increase in monsoon run-off into the eastern Mediterranean (yellow lines) are also indicated.

Figure 8 Planktonic foraminiferal stable carbon isotope records from core LC21, for the surface-dwelling G. ruber $\left(\delta^{13} \mathrm{C}_{\text {ruber }}\right.$; green) and sub-surface dwelling $N$. pachyderma $\left(\delta^{13} \mathrm{C}_{\mathrm{pac}}\right.$; purple) and G. inflata (panel a only; pink = normal test, blue = smooth test). Red Sea relative sea-level record (RSL; blue) and the Stanford et al. (2011) sea-level record (grey shading) as in Fig. 7. LC21 residuals (red with orange shading) as in Fig. 5). The timing of sapropels S1S5 (grey rectangles) and of cold episodes in the North Atlantic (the Younder Dryas, YD (Rasmussen et al., 2014), and Heinrich Stadials 1 (Álvares-Solas et al., 2011) and 11(Marino et al., 2015) (green rectangles) are indicated. Previously published data from LC21 are also shown in panels a and d, after conversion to the Grant et al. (2012) chronology: Total number of benthic foraminifera (Benthics/g; grey line with dots) and percent oxygen deficient species (ODS, grey shading), from Abu-Zied et al., (2008) (panel a); weight percent organic carbon ( $\mathrm{C}_{\text {org }}$; brown shading), isorenieratene concentration (black line with dots), and percent $F$. profunda (pink), after Marino et al (2007) and Grelaud et al. (2008) (panel d).

Figure 9 Timing of North Atlantic cold events, meltwater events and East African monsoon maxima under full interglacial conditions (a, b) and periods of glacial inceptions (c, d). Cooling in the North Atlantic region is indicated by the NGRIP ice-core temperature record (green; Kindler et al., 2014) (a,c,d) and by a maximum probability, alkenone-derived sea surface temperature (SST) record from ODP Site 976 (b) (grey; Martrat et al., 2014) on a radiometric-based chronology (Marino et al., 2015). A U/Th-dated speleothem $\delta^{18} \mathrm{O}$ record from the northern European Alps (NALPS; Boch et al., 2011), approximating Greenland temperature variations, is also shown (c,d). Cold events include the Younger Dryas (YD) (Rasmussen et al., 2014) and Heinrich Stadials 1 (Álvares-Solas et al., 2011) and 11 (Marino et al., 2015) (green rectangles), as well as events C21, C23, C24 (McManus et al., 1994). Meltwater events are inferred from rates of sea-level change (dRSL; blue) from Grant et al. $(2012,2014)$ (blue shading $=95 \%$ probability intervals of the maximum probability dRSL; line = maximum probability dRSL), and from Stanford et al. (2011) (grey shading in a; see 
Fig. 7). Also shown in (a) is MWP-1a at $46 \mathrm{~m} / \mathrm{kyr}$ (Deschamps et al., 2012). LC21 residuals (red, orange) and sapropel intervals (grey rectangles) are the same as in Fig. 5. 
Figure 1

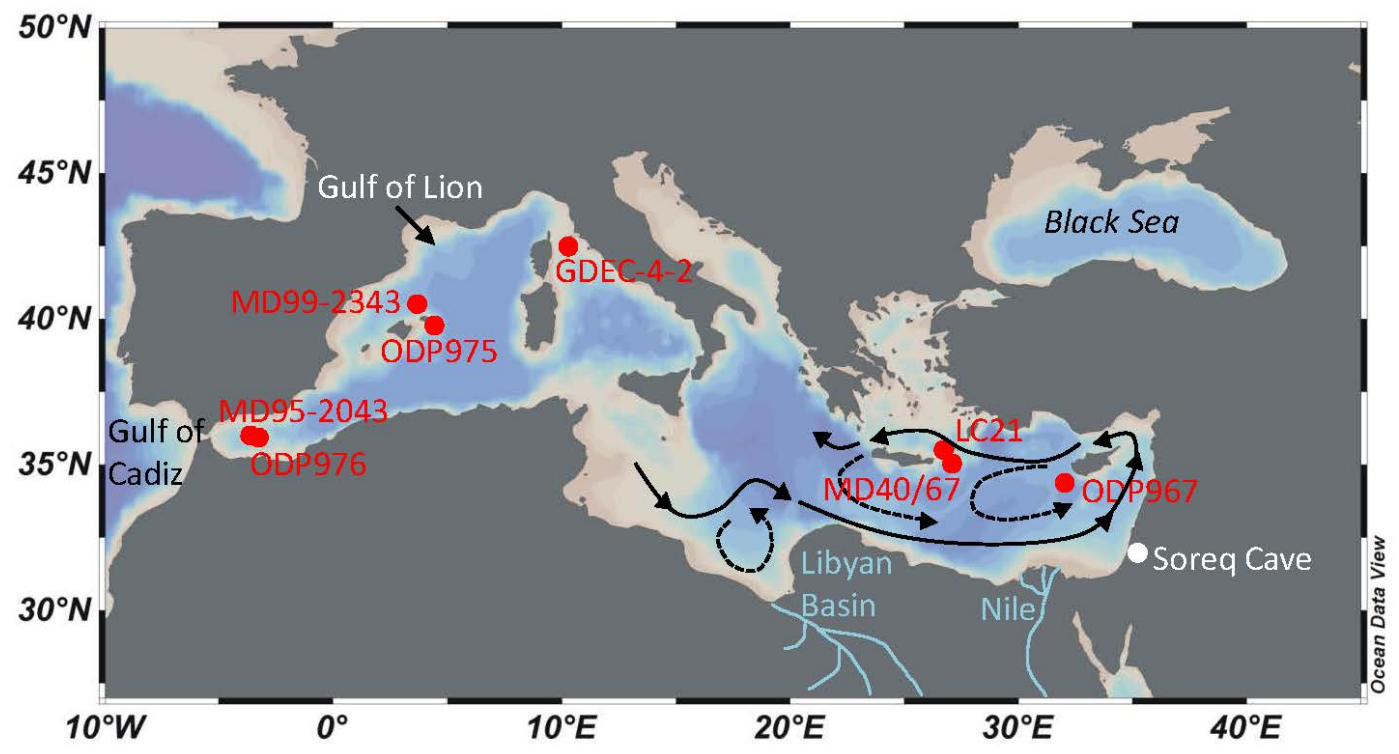

Figure 2

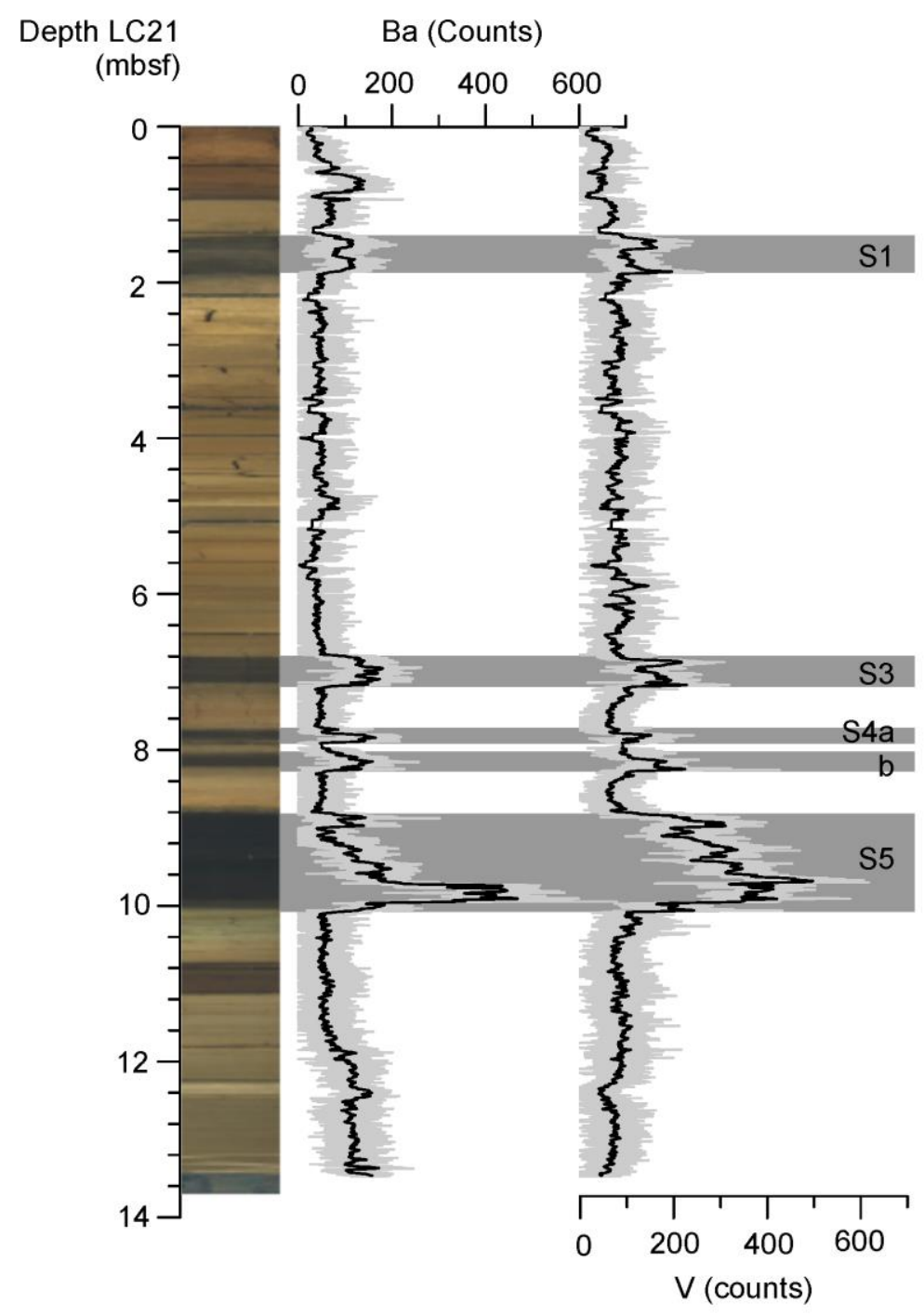


Figure 3

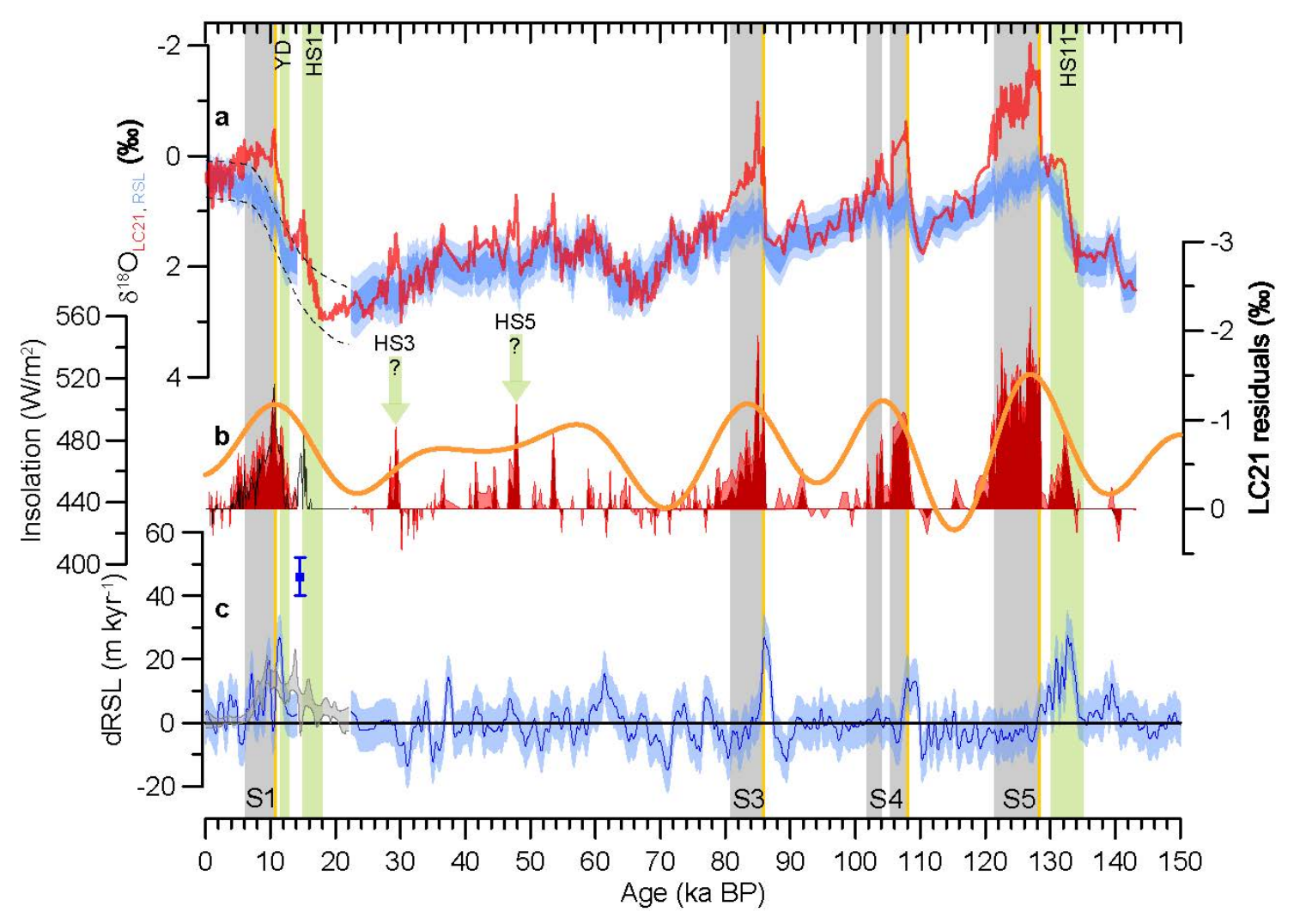

Figure 4
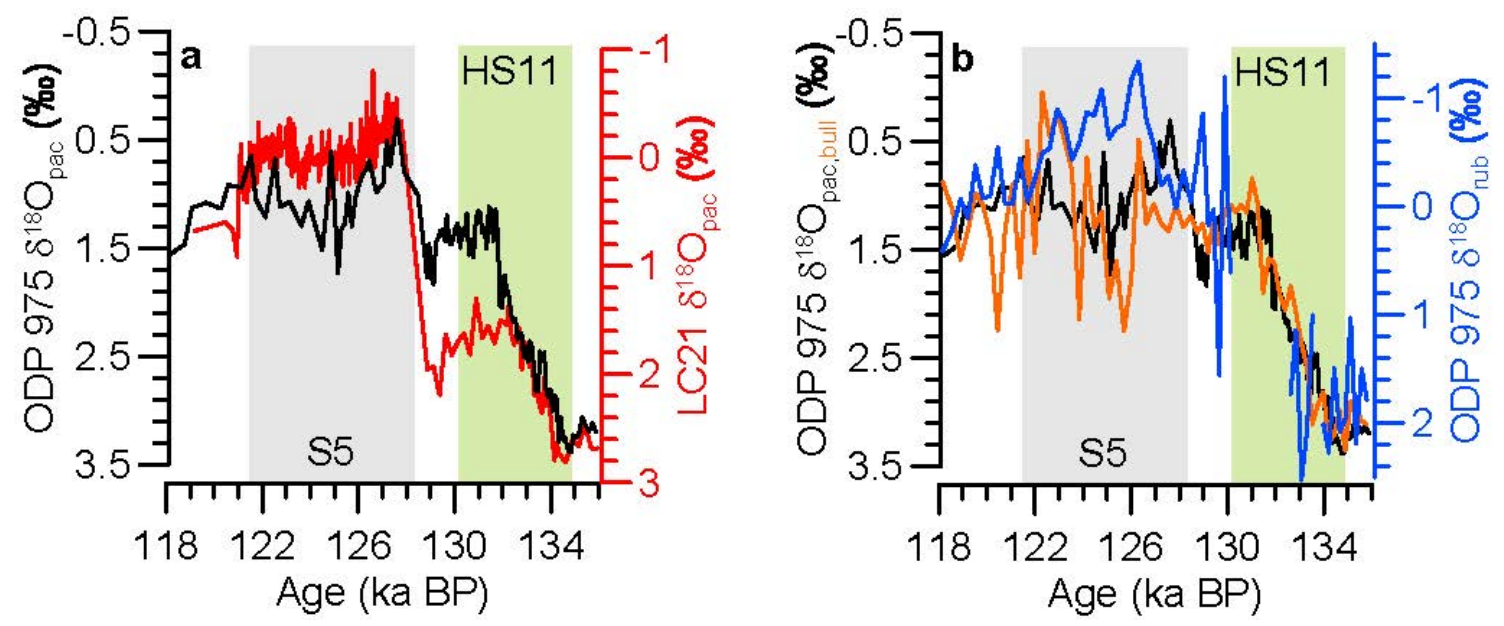
Figure 5
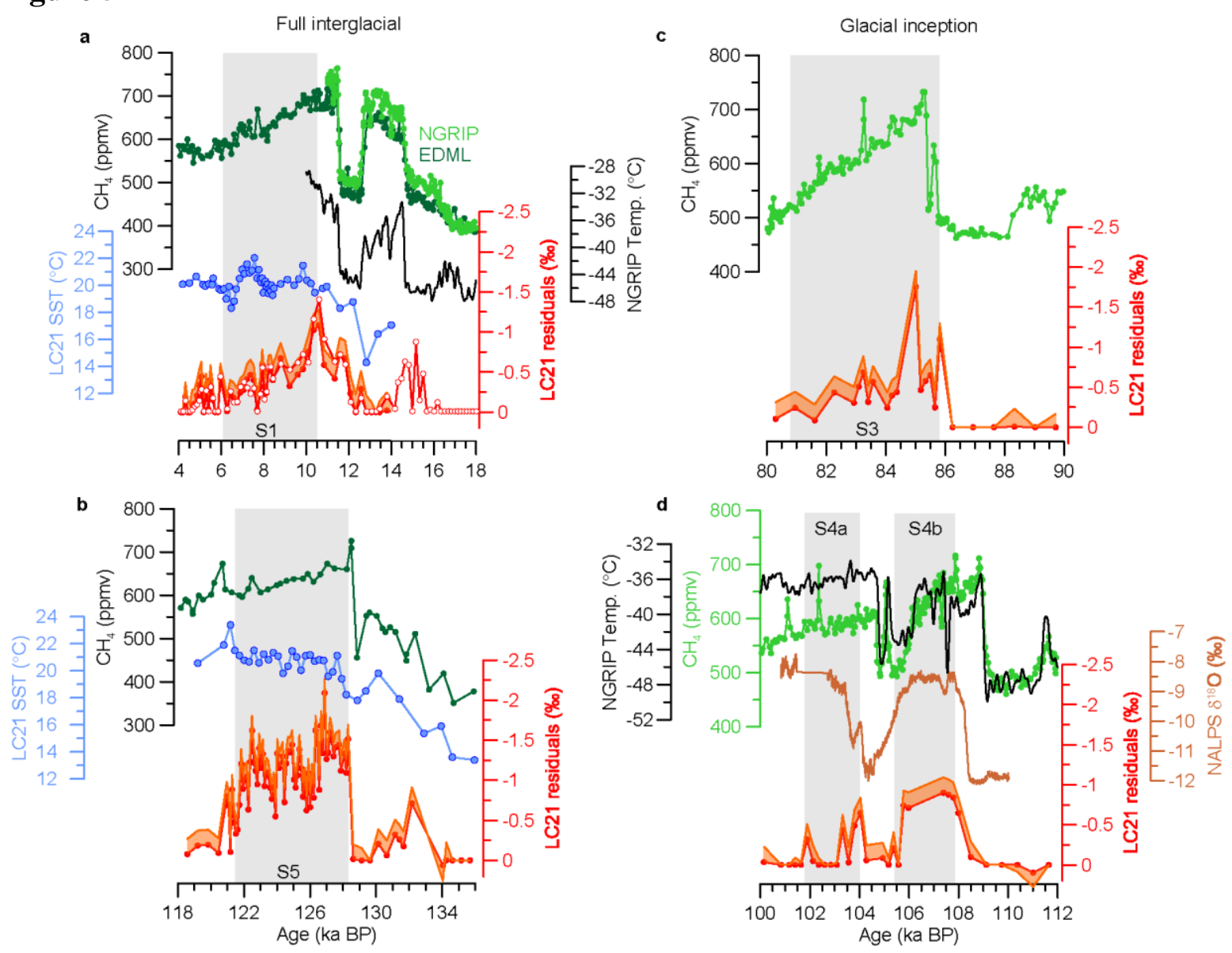

Figure 6

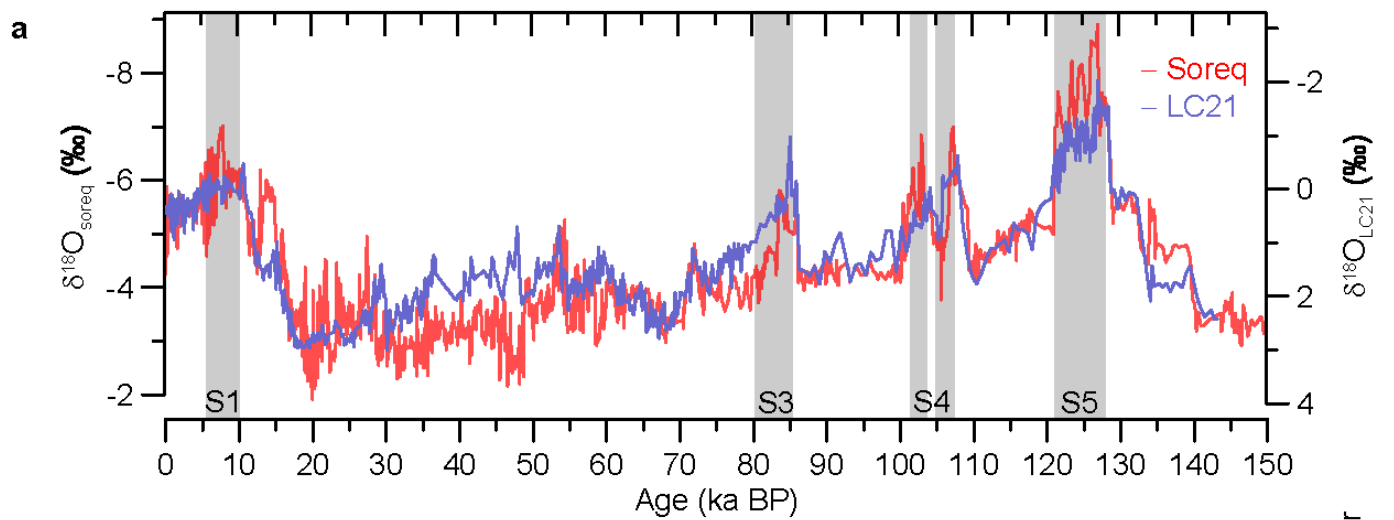

b
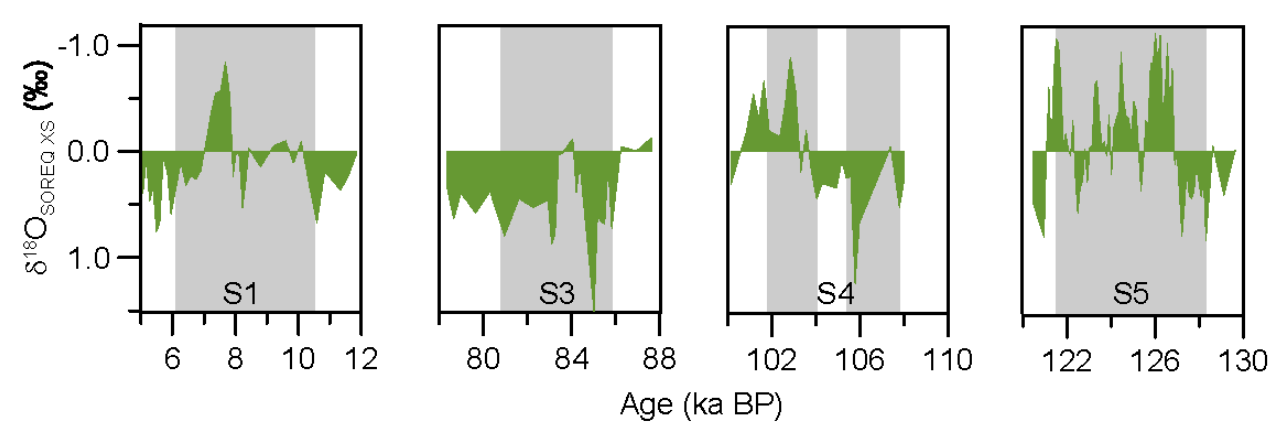

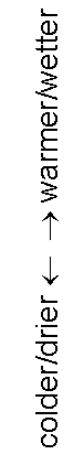




\section{Figure 7}
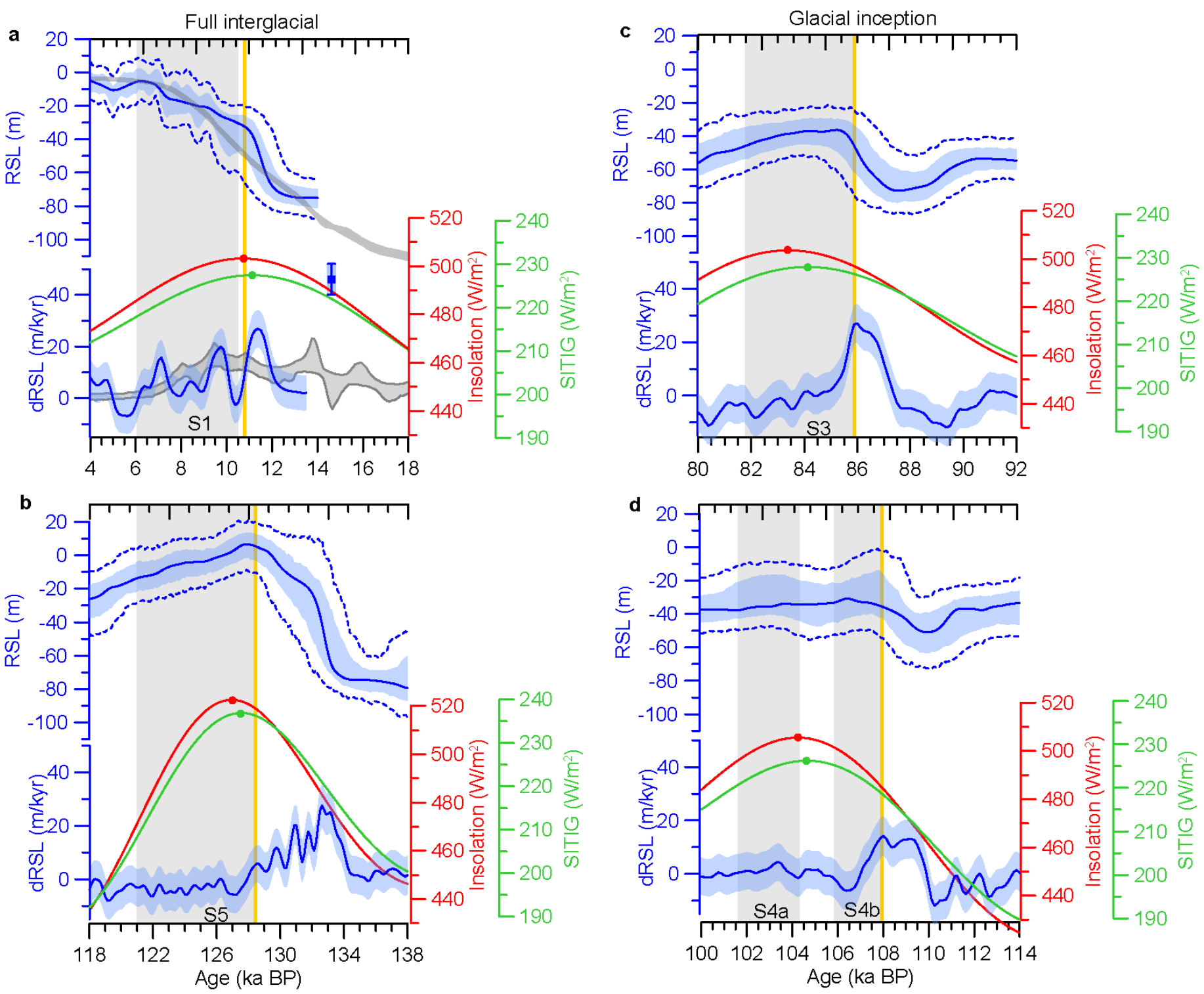
Figure 8
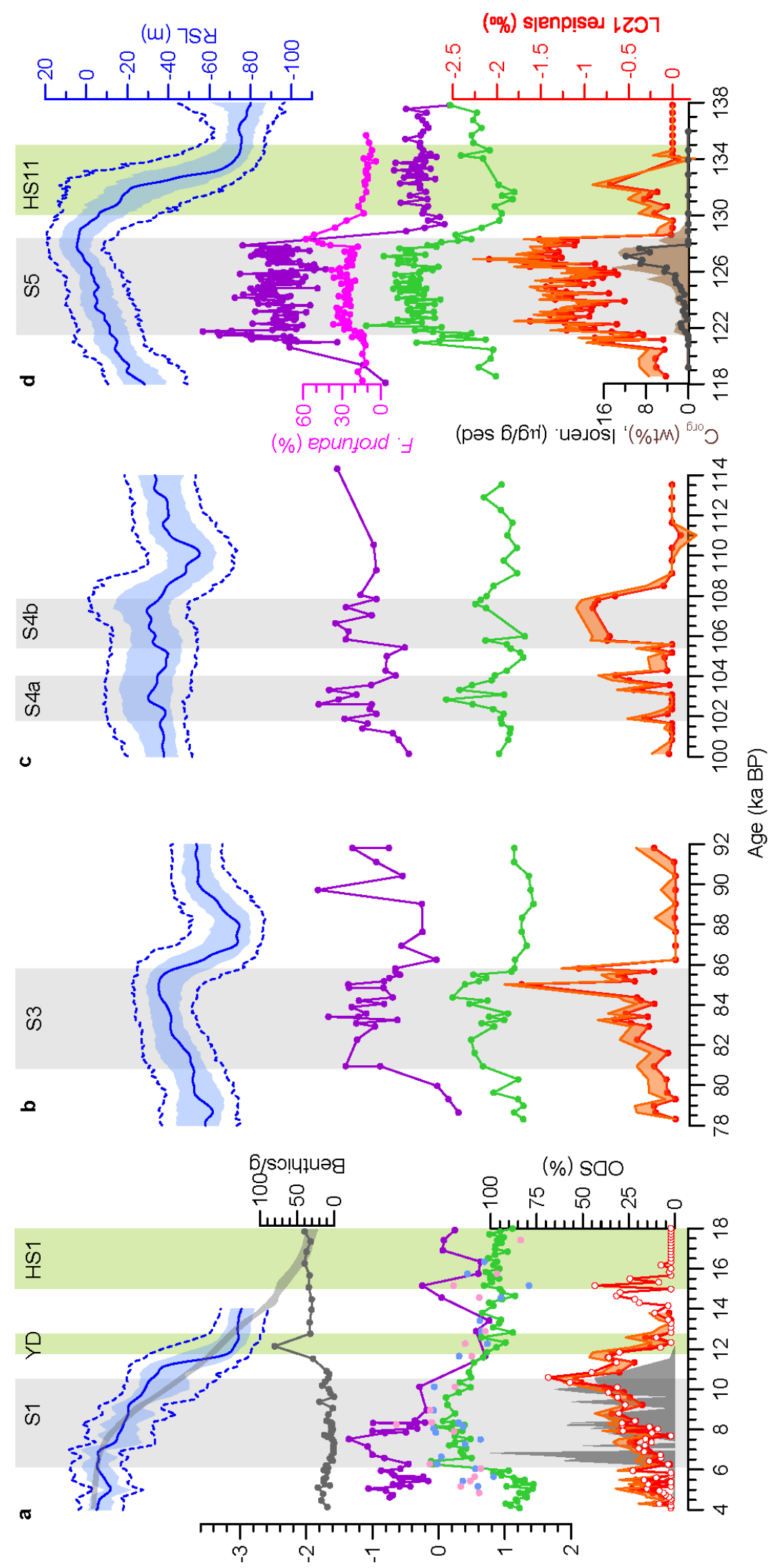

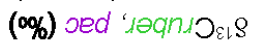




\section{Figure 9}
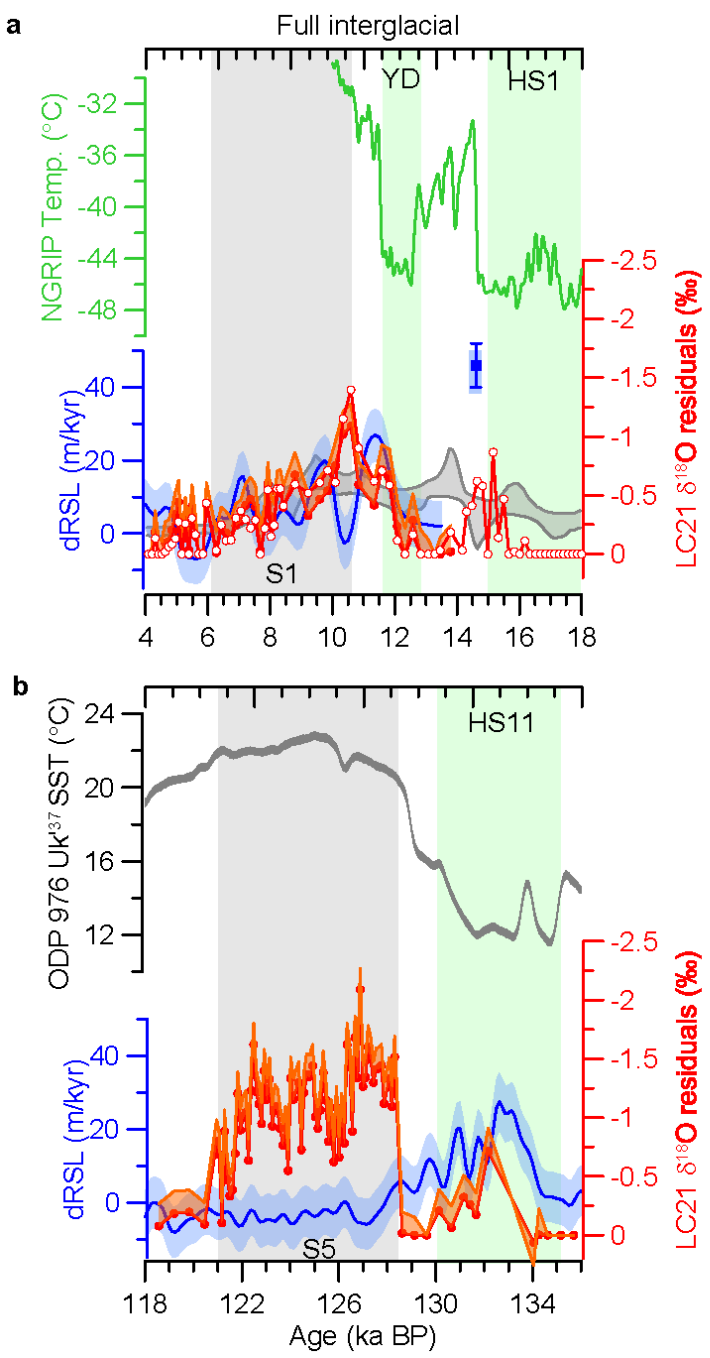
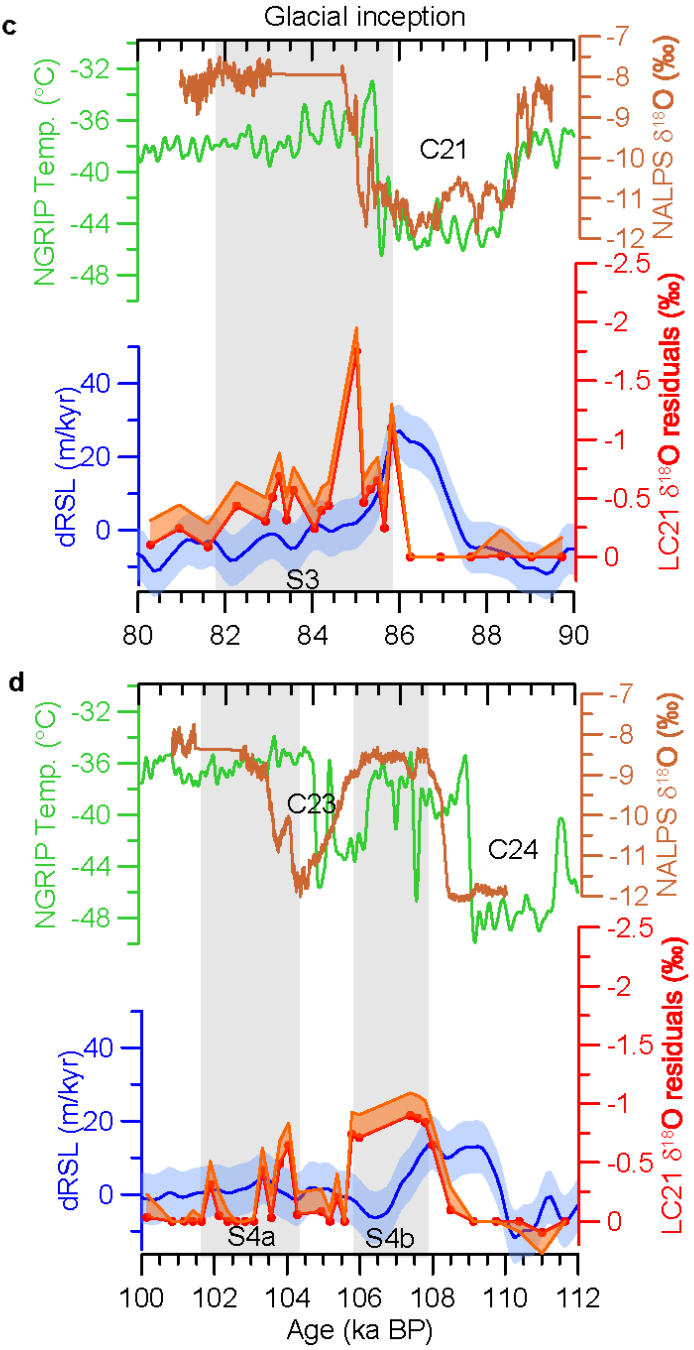
The timing of Mediterranean sapropel deposition relative to insolation, sea-level and African monsoon changes

K.M. Grant, R. Grimm, U. Mikolajewicz, G. Marino, M. Ziegler, E.J. Rohling

\section{Highlights}

1. Chronological framework for sapropels S1-S5, African monsoon, and sea-level change

2. Insolation-monsoon/sapropel phasings not systematic over the last glacial cycle

3. Meltwater release at glacial terminations delays monsoon and sapropel onset

4. Sea-level rise and monsoon run-off both important for sapropel formation 


\section{${ }^{*}$ Response to Reviewers}

\section{Editorial comments}

You would need to consider more clearly the fact of deglacial freshwater input into the western Mediterranean from other sources, e.g., the Alpine region specifically.

Done - see our responses to reviewer \#2.

On this note, Fig. 4 deals with your own data (ODP 975) only. However, MIS5e has been worked out in detail by Kandiano et al. 2014 (GPC).

We have amended Fig. 4 to include the results of Kandiano et al. (2014), and we now also discuss their results in comparison to ours over Heinrich Stadial 11 and termination 2 (lines 252-255).

\section{Reviewers' comments}

\section{Reviewer \#2 (Remarks to the Author):}

\# Figures. Figures presented by Grant and collaborators are very relevant. Nevertheless, Figure 1 have to be improved in order to facilitate the reading / understanding of the manuscript (and of the discussion in particular). I strongly invite the authors to add / draw on Figure 1: (i) the rivers (Nile, wadi-systems of North Africa, or Rhône, see below) that funnel freshwater into the eastern Mediterranean; (ii) the location of both marine (i.e., ODP 967, ODP 975, MD40/67) and continental (i.e., Soreq Cave) records mentioned in the main text; and (iii) the counter-clockwise surface flow pattern in the eastern Mediterranean discussed in part 3.2 of the manuscript.

\section{Done.}

\# Meltwater effects. In part 3.2 of their manuscript, Grant et al. "consider whether glacial meltwater or monsoon runoff best explain the negative LC21 $\delta 180$ residuals coincident with HS1 and HS11". This is an interesting / balanced discussion. Nevertheless, I'm puzzled with the idea that monsoon runoff could explain this signal during HS1/11 since it is well-known that monsoon runoff occurred at time of / or around precession minima...that means, for its last occurrence (ca. $12 \mathrm{kyr} \mathrm{BP}$ ), about $6 \mathrm{kyr}$ after the onset of HS1 (ca. $18 \mathrm{kyr} \mathrm{BP}$ ). As a result, is it really useful to discuss this possibility (i.e, monsoon runoff during HS1) in detail?... to finally conclude that "all these observations are in line with the argument that negative spikes in the LC21 residuals during major deglaciation events are likely due to North Atlantic (meltwater-related) salinity anomalies propagating into the eastern Mediterranean". To my view, this part of the discussion should be shortened (without consequences on the main conclusion of the manuscript).

We agree with the reviewer that this discussion is unnecessary and have cut it from the text.

I would invite the authors (i) to consider (recent) results from the Laurentide and European ice-sheets, rather than results from numerical modeling (Alvarez-Solas et al., 2011; see line 230), for the timing / source of the "large melting events during terminations" (and during HS especially) discussed in lines 228-233;

This is an interesting discussion but beyond the scope of the present study. The timing and sources of meltwater pulses (MWPs) are still much debated, especially regarding the Laurentide Ice Sheet, and most observations are for the last deglaciation only. For instance, Stanford et al. (2011QSR) provide a comprehensive synthesis of the timing and sources of MWPs during the last deglaciation, and show that there was significant waxing and waning among all global ice sheets ca 17.5-15.5 ka BP. Furthermore, in our case it is not necessary to consider specific meltwater sources into the North Atlantic when we are only concerned with whether the associated light $\delta^{18} \mathrm{O}$ anomalies were propagated into the Mediterranean. (Note that we do now cite evidence from the European Ice Sheet, but in reference to point (iii) below). 
(ii) to cite Sierro et al. (2005, Paleoceanography) (in addition to Rogerson et al., 2010, G3) when they discuss evidences for the flow of North Atlantic water into the Mediterranean during Heinrich Stadials (line 215-218);

Done. We've also added other citations to support this discussion (lines 216-229).

(iii) to consider a possible mediterranean origin for freshwater pulses at time of deglacial HS. Indeed, growing evidences suggest that the Rhône River (France) funnelled large volume of meltwater from the Alpine Ice-Sheet into the western Mediterranean during HS1 (e.g., Lombo-tombo et al., 2015, Sedimentary Geology). This source could contribute, in addition to the North Atlantic influence, to the decrease in the planktonic 180 observed in the western Mediterranean (ODP 975; Figure 4).

Done (lines 262 to 306). We have significantly expanded section 3.2 in order to consider these other potential sources (although we find, on balance, that the North Atlantic influence likely dominates the $\delta^{18} \mathrm{O}$ depletions in question).

\# Others.

The authors discuss the evidences for humidity increases in winter during intervals of precession minima. Recent results published by Toucanne et al. (2015, Quaternary Science Reviews) and Bosmans et al. (2015, Quaternary Science Reviews) should be cited / added here. On this point, it is interesting to note that the $\delta 18$ Osoreq xs support this hypothesis.

We agree with the reviewer that the Toucanne and Bosmans papers should be cited here (these studies had not been published at the time of our manuscript submission). In addition, in light of the continued debate regarding humidity increases during sapropel deposition/precession minima, we have expanded section 3.3.2 (see lines 356-411 and 436-449) so that it now includes a more lengthy discussion of the key evidence contributing to this debate, and how our $\delta^{18} \mathrm{O}_{\text {SOREQ Xs }}$ record fits with this evidence.

Considering that this humidity is likely related to enhanced westerlies over the northern Mediterranean borderlands (see references above), it should be relevant to consider this forcing as well in the process leading to sapropel deposition.

At face value this appears to be a logical comment. However, it assumes $i$ ) that humidity did indeed increase during the sapropel intervals considered here, $i i)$ that a humidity increase was related to enhanced westerlies, and - most importantly - iii) that an increase in humidity would cause sufficient surface buoyancy forcing to inhibit deep-water ventilation (and thus promote sapropel formation). These points are now covered in our expanded section 3.3.2. We find that $i$ ) on balance the evidence suggests that only for sapropel S5 is there strong, unambiguous evidence for increased humidity; ii) recent modelling disputes the 'enhanced westerlies' hypothesis, and iii) the effect of increased humidity on surface buoyancy forcing was likely secondary to monsoon- and sea-level driven surface-water freshening. Nonetheless, the effect of increased humidity on surface buoyancy forcing remains poorly constrained and so we cannot rule it out; we have amended the first paragraph of section 5.3 (lines 608-615) to reflect this.

- Lines 396-397: the authors write: "An alternative explanation is that negative peaks in LC21 residuals prior to S1 (ca 11.5-15.5 ka BP) may parlty relate to...". Considering that S1 is dated at 10.2-6.4 ka BP (e.g., Mercone et al., 2000, Paleoceanography), and that the negative peaks in LC21 prior to S1 occurred between 16-14 ka BP and from ca. $13 \mathrm{ka} \mathrm{BP} \mathrm{(Figure} \mathrm{5a),} \mathrm{I} \mathrm{do} \mathrm{not} \mathrm{understand} \mathrm{the} \mathrm{reference} \mathrm{to} \mathrm{"(ca} \mathrm{11.5-15.5} \mathrm{ka} \mathrm{BP)"}$ in line 397. Please correct (or explain).

We have re-written this sentence to avoid confusion (the reference 'ca 11.5-15.5 ka BP' was not to S1 but to the pre-S1 interval of negative residuals). We now clarify the timing of negative residuals in line 508.

- The reference "(Taylforth et al., 2014)" (line 728) cannot be found in the 'Reference list'. 


\section{Reviewer \#3 (Remarks to the Author):}

My only concern is the following: authors make a linear relationship between meltwater and sea level rise in the Mediterranean Sea and then sea level rise and lower salinity waters. Recently (Pinardi et al., Journal of Climate, 2014, explained the precise relationship between Gibraltar inflow, salinity and mean sea level in the Mediterranean Sea. It is shown that this relationship is not simple but has also stochastic components due to the balance between the Mediterranean surface water budget and the Gibraltar inflow. Atlantic ice melting in the Mediterranean Sea would in fact enhance the stochasticity of the Gibraltar inflow contribution to mean sea level tendency in the Mediterranean Sea and this could account at least in part for the differences found between S3, S4 and sea level changes with respect to S1-sea level relationship. In addition changes in salinity induced by a larger Gibraltar inflow from the Atlantic could be different in the different cases. I am suggesting that the authors reflect about the possibility of also considering a complex relationship between meltwater events, Gibraltar inflow changes, sea level rise and freshening of the Mediterranean Sea.

The paper that the reviewer refers to considers present-day mean sea-level changes over a decade, where the maximum amplitude of sea-level variations is $\sim 1 \mathrm{~m}$. Hence, while he/she is correct that such variability has a strong steric component and is stochastic, on the timescales that we consider sea-level variability is tens of $\mathrm{m}$ and is mostly driven by glacioeustasy. Nonetheless, we now provide more detail about the relationship between changes in sea level and Mediterranean salinity, and explicitly state that this relationship in nonlinear (lines 627-639).

Furthermore, the statement at line 545-546: "Falling sea level would have led to increasing Mediterranean surface-water salinity, due to inflow of more saline global ocean waters" is probably too simplistic. I recommend to weaken the statement.

We have re-written this statement more comprehensively (lines 664-667), so that the well-understood link between falling (global) sea level and an increase in Mediterranean salinity on glacial-interglacial timescales is explained in more detail and referenced (see also previous comment).

Line 40: please add reference to paper about all the sapropel deposition factors:

D. Bianchi, M. Zavatarelli, N. Pinardi, R. Capozzi, L. Capotondi, C. Corselli and S. Masina, 2006. "Simulations of ecosystem response during the sapropel S1 deposition event." Palaeogeography, Palaeoclimatology, Palaeoecology, 235, pp.

265-287, doi:10.1016/j.palaeo.2005.09.032

Done. 